\title{
Organization of the Anterior Limb of the Internal Capsule in the Rat
}

\author{
DVeronique Coizet, ${ }^{1,2 *}$ (Darah R. Heilbronner, ${ }^{4 \star}$ Carole Carcenac, ${ }^{1,2}$ Philippe Mailly, ${ }^{3}$ Julia F. Lehman, ${ }^{4}$ \\ @Marc Savasta, ${ }^{1,2}$ Oivier David, ${ }^{1,2}$ Jean-Michel Deniau, ${ }^{5}{ }^{\circ}$ Henk J. Groenewegen, ${ }^{6}$ and ${ }^{\circledR S}$ Suzanne N. Haber ${ }^{4}$ \\ ${ }^{1}$ INSERM, U1216, F-38000 Grenoble, France, ${ }^{2}$ University of Grenoble Alpes, Grenoble Institut des Neurosciences, GIN, F-38000 Grenoble, France, ${ }^{3}$ INSERM \\ UMR 952, Centre National de Recherche Scientifique UMR 7224, Université Pierre et Marie Curie, Paris Cedex 05, France, ${ }^{4}$ Department of Pharmacology \\ and Physiology, School of Medicine, University of Rochester, Rochester, New York 14642, ${ }^{5}$ INSERM U667, Collège de France, 75231 Paris Cedex 05, France, \\ and ${ }^{6}$ Department of Anatomy and Neurosciences, Neuroscience Campus Amsterdam, VU University Medical Center, 1007 MB Amsterdam, The \\ Netherlands
}

Dysfunction of the orbitofrontal (OFC) and anterior cingulate (ACC) cortices has been linked with several psychiatric disorders, including obsessive-compulsive disorder, major depressive disorder, posttraumatic stress disorder, and addiction. These conditions are also associated with abnormalities in the anterior limb of the internal capsule, the white matter (WM) bundle carrying ascending and descending fibers from the OFC and ACC. Furthermore, deep-brain stimulation (DBS) for psychiatric disorders targets these fibers. Experiments in rats provide essential information on the mechanisms of normal and abnormal brain anatomy, including WM composition and perturbations. However, whereas descending prefrontal cortex (PFC) fibers in primates form a well defined and topographic anterior limb of the internal capsule, the specific locations and organization of these fibers in rats is unknown. We address this gap by analyzing descending fibers from injections of an anterograde tracer in the rat ACC and OFC. Our results show that the descending PFC fibers in the rat form WM fascicles embedded within the striatum. These bundles are arranged topographically and contain projections, not only to the striatum, but also to the thalamus and brainstem. They can therefore be viewed as the rat homolog of the primate anterior limb of the internal capsule. Furthermore, mapping these projections allows us to identify the fibers likely to be affected by experimental manipulations of the striatum and the anterior limb of the internal capsule. These results are therefore essential for translating abnormalities of human WM and effects of DBS to rodent models.

Key words: cingulate; deep-brain stimulation; homology; orbitofrontal; prefrontal cortex; white matter

Significance Statement

Psychiatric diseases are linked to abnormalities in specific white matter (WM) pathways, and the efficacy of deep-brain stimulation relies upon activation of WM. Experiments in rodents are necessary for studying the mechanisms of brain function. However, the translation of results between primates and rodents is hindered by the fact that the organization of descending WM in rodents is poorly understood. This is especially relevant for the prefrontal cortex, abnormal connectivity of which is central to psychiatric disorders. We address this gap by studying the organization of descending rodent prefrontal pathways. These fibers course through a subcortical structure, the striatum, and share important organization principles with primate WM. These results allow us to model primate WM effectively in the rodent.

\section{Introduction}

The prefrontal cortex (PFC) is composed of anatomically and functionally specialized subregions involved in reinforcement-

Received Oct. 25, 2016; revised Dec. 28, 2016; accepted Jan. 6, 2017.

Author contributions: V.C. and S.N.H. designed research; V.C., S.R.H., C.C., P.M., J.F.L., M.S., 0.D., J.-M.D., H.J.G., and S.N.H. performed research; J.-M.D. and H.J.G. contributed unpublished reagents/analytic tools; V.C., S.R.H., and S.N.H. analyzed data; V.C., S.R.H., O.D., H.J.G., and S.N.H. wrote the paper.

This work was supported by the National Institutes of Health (Grant P50MH106435 to S.N.H. and Grant F32MH103931 to S.R.H.) and INSERM.

The authors declare no competing financial interests. based learning, response selection, attention, and behavioral flexibility (Haber and Behrens, 2014). The orbitofrontal cortex (OFC) and anterior cingulate cortex (ACC) are associated with several psychiatric disorders, including obsessive-compulsive

\footnotetext{
*V.C. and S.R.H. contributed equally to this work.

Correspondence should be addressed to Suzanne N. Haber, Professor, Dept. of Pharmacology and Physiology, University of Rochester School of Medicine and Dentistry, 601 Elmwood Ave., Rochester, NY 14642. E-mail: suzanne_haber@urmc.rochester.edu.

DOI:10.1523/JNEUROSCI.3304-16.2017

Copyright $\odot 2017$ the authors $\quad 0270-6474 / 17 / 372539-16 \$ 15.00 / 0$
} 
disorder (OCD), major depressive disorder, posttraumatic stress disorder, and addiction (Mayberg et al., 1997; Volkow et al., 2011b; Milad and Quirk, 2012; Haber and Heilbronner, 2013). The anterior limb of the internal capsule (ALIC) in human and nonhuman primates carries the ascending and descending fibers from the OFC and ACC. In primates, these fibers are organized such that the ventral ALIC carries fibers from the ventral medial PFC and OFC and the dorsal PFC fibers are located more dorsally (Lehman et al., 2011; Jbabdi et al., 2013). Importantly, diseases linked to the OFC and ACC show abnormal volume, fractional anisotropy, and diffusivity generally in the internal capsule, with some studies demonstrating these abnormalities specifically in the ALIC (Lang et al., 2006; Wobrock et al., 2008; Zou et al., 2008; Duran et al., 2009; Jia et al., 2010; Togao et al., 2010; Upadhyay et al., 2010; Nakamae et al., 2011; Zhu et al., 2011; Koch et al., 2014; Kuan et al., 2015). Indeed, the ALIC is a target for deep-brain stimulation (DBS) and ablative surgery for both depression and OCD (Malone et al., 2009; Greenberg et al., 2010a).

The rat represents an essential animal model with which to investigate normal physiological and behavioral functions and the mechanisms that underlie abnormal behaviors (Crawley, 1985; Cenci et al., 2002; Dalley et al., 2004; Hamani et al., 2014; Cosgrove et al., 2016). The rat ACC is divided into the infralimbic (IL), prelimbic (PL), and cingulate (CG) cortices (Heidbreder and Groenewegen, 2003; Dalley et al., 2004; Schilman et al., 2008). Collectively with the OFC, we refer to these regions as the OCIP (for orbital-cingulate-infralimbic-prelimbic cortex). Importantly, high-frequency stimulation (HFS) of the striatum and the fiber bundles that course through it are used as a model for understanding the mechanisms underlying the effects of DBS (McCracken and Grace, 2007; Rodriguez-Romaguera et al., 2012; Hamani et al., 2014). Despite the importance of connectivity studies across species, the white matter (WM) abnormalities observed in disease, and the need for a rodent model for a mechanistic approach, little is known about the trajectories and organization of OCIP fibers in rats. Therefore, the characterization of the descending OCIP fiber bundles in the rat is crucial to our understanding of how experimental manipulations such as DBS modulate PFC connections and functions. Moreover, understanding the orientation of these fibers passing through the striatum to the thalamus and brainstem is important for preparing tissue slices that preserve corticosubcortical connections (Lee et al., 2007; Cruikshank et al., 2012). Although the rat does not have an organized and compact ALIC like that found in the primate, the striatum in both species is filled with small WM fascicles that contain dense bundles of passing cortical fibers (Berendse et al., 1992; Lehman et al., 2011). Our goal was to determine whether these fascicles are arranged such that they represent the rat homolog of the topographically organized primate ALIC.

Here, we focus on the rat ALIC and the organization of pathways that OCIP fibers take in their course through the striatum to reach the thalamus. Our results show that many of the WM fascicles embedded within the striatum contain topographic cortical descending projections and therefore can be viewed as the ALIC in the rat. Importantly, the topographic pattern is similar to that in the primate.

\section{Materials and Methods}

Overview. After recognized subdivisions of the rodent PFC (Heidbreder and Groenewegen, 2003; Dalley et al., 2004; Schilman et al., 2008), we injected the selective anterograde tracer Phaseolus vulgaris leucoagglutinin (PHA-L) into four regions in rats: the CG, PL, and IL of the medial $\mathrm{PFC}$ and the ventral/lateral orbital area (in both areas VO and LO:
VOLO) of the ventral surface of the frontal lobe. For each case, the injection site and fiber bundles passing from the cortex through the striatum to the thalamus and brainstem structures were charted. The charts consisted of outlines of the small bundles, creating tube-like structures when rendered in 3D. Each individual drawing was then combined into a single 3D model to reveal the topography of PFC descending projections.

Surgery and tissue preparation. We used 10 adult male Sprague Dawley rats (weight 250-350 g; Charles River Laboratories) for the tracing study (Fig. 1). Surgical procedures were applied in strict accordance with the European Communities Council Directive 86/609/EEC, 1986. Animals were anesthetized by an injection of sodium pentobarbital (Nembutal, $40 \mathrm{mg} / \mathrm{kg}$, i.p.; Sanofi). Additional injections of ketamine $(30 \mathrm{mg} / \mathrm{kg}$, i.m.) were occasionally necessary to adjust the level of anesthesia. In addition, $10 \%$ lidocaine was used as local anesthetic for the skin at the sites of incision. The anesthetized animals were placed in a stereotaxic frame. Body temperature was maintained between $36^{\circ} \mathrm{C}$ and $38^{\circ} \mathrm{C}$ by the use of a homeothermic mat. The brain was exposed through small burr holes in the skull and the anterograde tracer PHA-L (Vector Laboratories) was injected unilaterally in single areas of the PFC. The coordinates were derived from the atlas of Paxinos and Watson (1986). As illustrated in Figures 1 and 2, PHA-L was injected deep into the anterior and central part of PL, the anterior part of CG, and extended over the entire length of IL and VOLO.

The tracer PHA-L was ejected iontophoretically [ $5 \mu \mathrm{A}$ anodal current applied to a $2.5 \%$ solution in $0.1 \mathrm{M}$ phosphate buffer (PB 0.1 ), $7 \mathrm{~s}$ on/off for 10-20 min per injection site] through glass micropipettes (CG 150; Clark) with an internal tip diameter of $20-30 \mu \mathrm{m}$. After allowing $7 \mathrm{~d}$ for the transport of tracers, animals were deeply reanesthetized with sodium pentobarbital (Nembutal, $160 \mathrm{mg} / \mathrm{kg}$, i.p.) and perfused transcardially with $0.9 \%$ saline followed by a fixative containing $4 \%$ paraformaldehyde and $0.05 \%$ glutaraldehyde in $\mathrm{PB}, \mathrm{pH}$ 7.4. After an overnight fixation period, serial coronal sections $(50 \mu \mathrm{m})$ were cut on a freezing microtome and collected in PB to be processed for PHA-L. A reliable plane of section was obtained by cutting the brains dorsoventrally at the level of the cerebellum along a vertical plane tilted $18^{\circ}$ toward the rostral part of the brain and sections were cut parallel to this plane. The free-floating sections were washed with $\mathrm{PB}$, followed by $0.05 \mathrm{M}$ Tris- $\mathrm{HCl}$ (Merck) supplemented with $0.15 \mathrm{M} \mathrm{NaCl}$, pH 7.6 (Tris-buffered saline, TBS-T) and $0.5 \%$ Triton X-100 (TBS-Tx; Merck). They were subsequently incubated for $48 \mathrm{~h}$ at $4^{\circ} \mathrm{C}$ in goat anti-PHA-L (1:1000 dilution; Vector Laboratories) in TBS-T. The next day, after rinsing (all intermediate steps between different incubations include three washes of the indicated buffer for 10 min each) with TBS-T, the sections were incubated for $18 \mathrm{~h}$ at room temperature in biotinylated rabbit anti-goat IgG followed by incubation in avidin-biotin-peroxidase complex (Vector Laboratories) in TBS-Tx for $1.5 \mathrm{~h}$ at room temperature. After rinsing with Tris-HCl, PHA-L was revealed by standard diaminobenzidine procedures. Staining was intensified by incubating the tissue for 5-15 $\mathrm{min}$ in a solution of $0.05 \% 3,3$ diaminobenzidine tetra-hydrochloride, .025\% cobalt chloride, $0.02 \%$ nickel ammonium sulfate, and $0.01 \% \mathrm{H}_{2} \mathrm{O}_{2}$ to yield a black section product. Sections were mounted onto gel-coated slides, dehydrated, defatted in xylene, and coverslipped with Permount.

Data analysis. Coronal sections were digitized using a light microscope (Eclipse 80i, TRIBVN, 2.9.2 version; Nikon) coupled to the ICS Framework computerized image analysis system (TRIBVN, 2.9.2 version; Nikon) and a Pike F-421C camera (Allied Vision Technologies). Digitized images were converted into a .tiff format and individually exported in Adobe Photoshop to create individual .tiff files with the same dimension. A stack of 2D coronal sections was then created using Cygwin and IMOD package software (Boulder laboratory for 3D Electron Microscopy of Cells, University of Colorado, Boulder, CO; Kremer et al., 1996). Sections were aligned with the Midas program from IMOD using manual rigid body transformations as described previously (Mailly et al., 2010). The stack was open in IMOD, where the structures of interest were delineated, including the corpus callosum (CC), the striatum, the anterior commissure, the internal capsule, and the globus pallidus. (Here, we refer to the Paxinos and Watson (1986) delineation of the internal capsule, not including the 


\begin{tabular}{|c|c|c|c|c|c|}
\hline Case number & $\begin{array}{l}\text { Brain } \\
\text { region }\end{array}$ & Injection site & Case number & $\begin{array}{l}\text { Brain } \\
\text { region }\end{array}$ & Injection site \\
\hline 23110601 & $\mathrm{CG}$ & & 90045 & IL & \\
\hline 25020803 & $\mathrm{CG}$ & & 93283 & IL & \\
\hline 18090901 & PL & & 08030701 & VOLO & \\
\hline 18090902 & PL & & 08030702 & VOLO & \\
\hline 16090902 & PL & & 20080702 & VOLO & \\
\hline
\end{tabular}

Figure 1. List of animal cases and injection sites. Selected cases for individual illustration are shown in bold. Photomicrographs of coronal sections are centered on the maximal extent of the tracer. The delineation of the structures was made using the atlas of Paxinos and Watson (1986) as a reference. Al (V, D), agranular insular cortex (ventral and dorsal); $\mathrm{Cl}$, claustrum; $\mathrm{Gl}$, granular insular cortex; $\mathrm{M} 1$ and $\mathrm{M} 2$, motor cortex 1 and 2; $\mathrm{M0}$, medial orbital cortex; primary somatosensory cortex, jaw region.
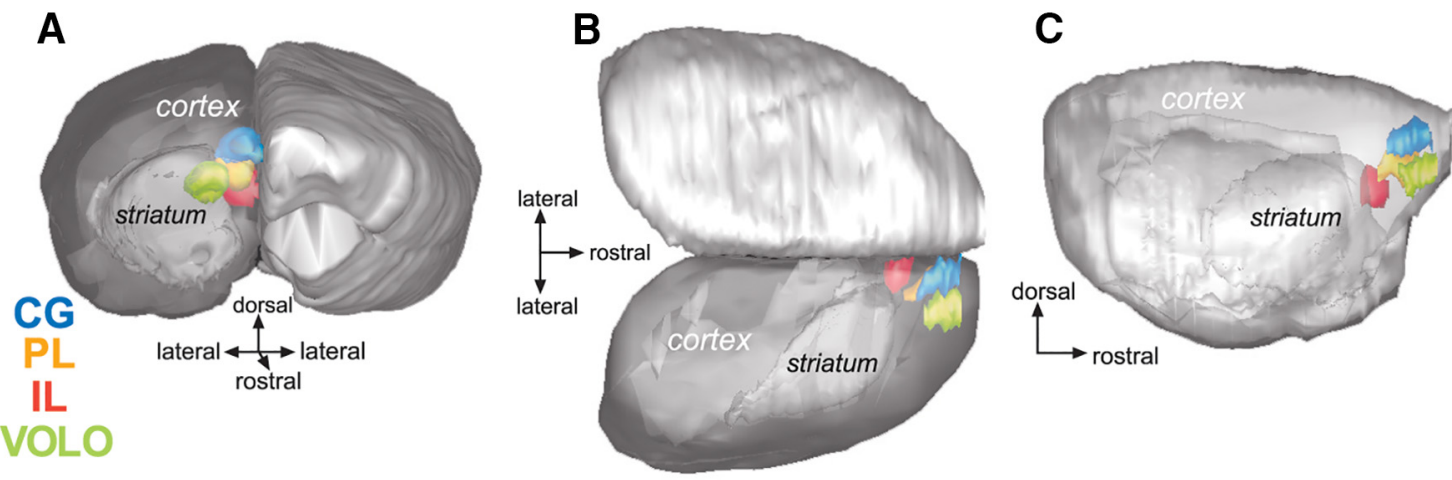

Figure 2. Illustration of the injection sites in the four prefrontal cases selected for 3D reconstruction. Each color codes for a different injection site, with CG in blue, PL in orange, IL in red, and VOLO in green. Position and extent of injection sites in the 3D model examined from a frontal coronal view (A), top horizontal view (B), and sagittal view (C). 

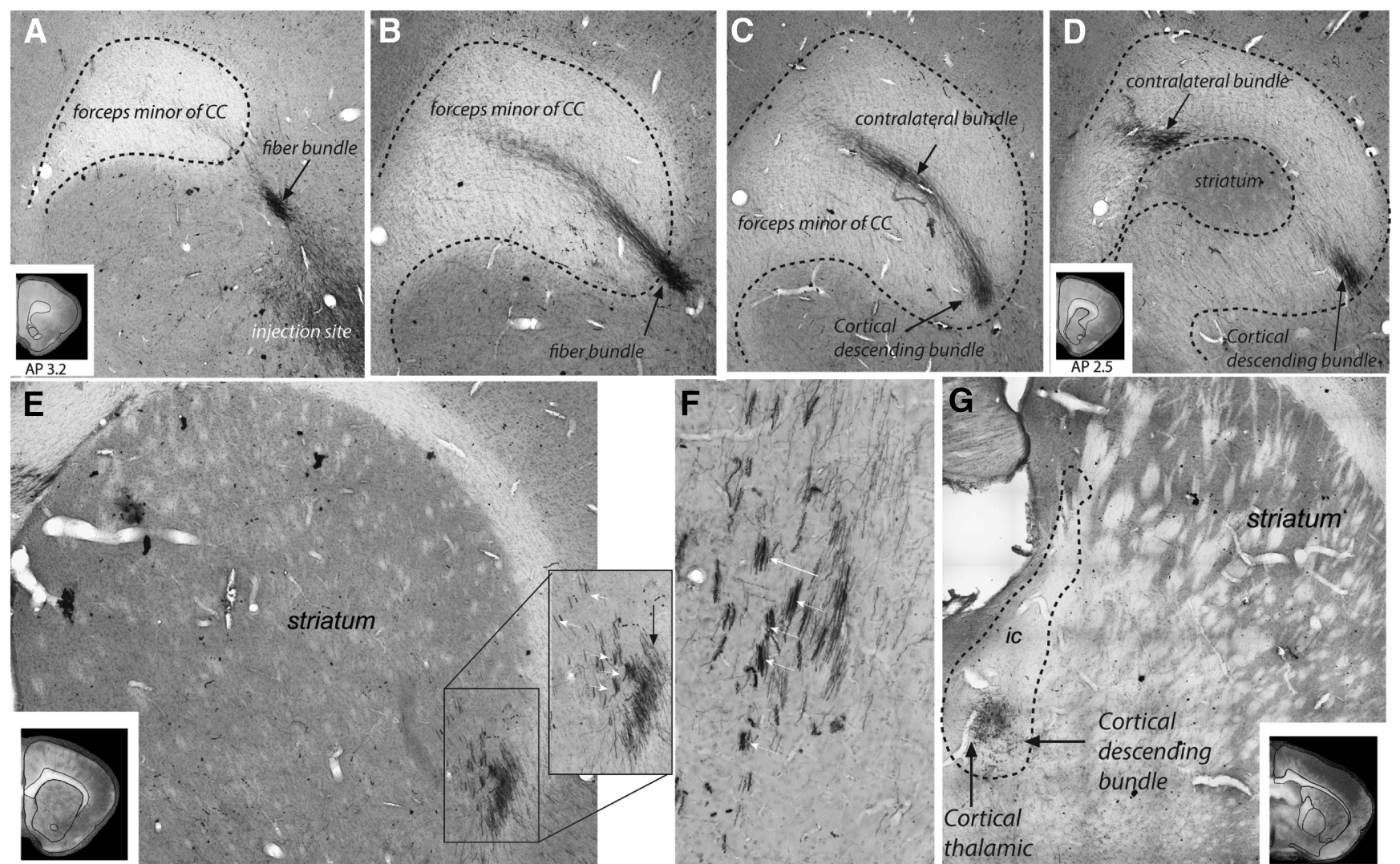

AP 1.6
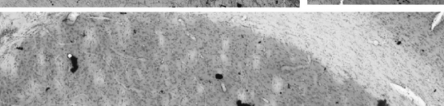
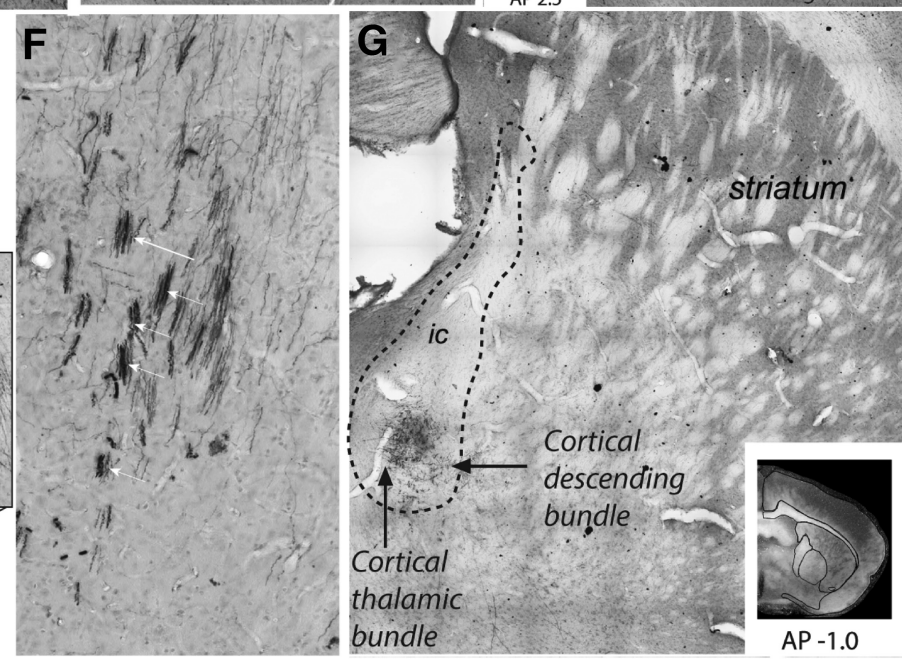

Figure 3. Photomicrographs of OCIP descending pathways. $\boldsymbol{A}-\boldsymbol{D}$, Photomicrographs of coronal rat brain sections centered on the right $C(\mathrm{C}$ at different anteroposterior levels with $\boldsymbol{A}$ the most rostral and $\boldsymbol{D}$ the most caudal section. OCIP (for this illustration, an LO Case) axons leave the injection sites and travel toward the CC, where they split into a contralateral and a descending bundle. $E, F, O C I P$ fibers enter the striatum (black arrow) and divide into small fascicles (white arrows) to travel toward the internal capsule. $G, O C I P$ axons embedded within the internal capsule. At this level, two separate bundles can be distinguished: a dense cortical thalamic bundle and a cortical bundle that will continue to descend. AP, Anterior-posterior distance from bregma $(\mathrm{mm})$.

proposed ALIC.) For each case, the injection site, descending bundles of labeled axons, and striatal and thalamic terminals were outlined in IMOD directly on the digitized images. This process also created a 3D reconstruction of descending bundles and terminals for each case. A bundle was defined as a group of labeled fibers traveling together to a specific area of the brain (i.e., the thalamus and/or the brainstem). Note that the form of the bundles can vary from dense to sparse. Moreover, according to the orientation of the fibers relative to the slice cut, they can appear as small dots or lines of axons. Bundles were outlined and analyzed visually across sections to determine their termination points. While traveling to their targets, bundles can separate into several smaller, physically separate groups of fibers called fascicles. However, a single bundle may be spread over multiple fascicles that share a termination point.

To compare across cases, a single, representative case was chosen from each OCIP region. These representative models were then merged together into a reference model. This reference model (introduced in Mailly et al., 2010) was developed from one animal by sampling one in four sections throughout the entire brain using frozen and Nissl-stained sections. The specific reference brain was chosen based on its high quality of perfusion and staining and minimal distortion during cutting. Data from each case (injection site, descending bundles, and striatal and thalamic terminal fields) were transported into the reference brain using landmarks of key internal structures. After the transposition of projections from each case, every contour placed in the reference model was checked with the original case for medial/lateral, dorsal/ventral, and anterior/posterior placement and its relative size. This ensured that each of the fiber bundles from the different cases was placed accurately with respect to its position and the proportion of the WM tract that it occupied. To facilitate the characterization of the topography between OCIP bundles in the representative model, a small tube was plotted and modeled in the center of each bundle.

\section{Results}

\section{General pattern of projection}

Fiber bundles leave the injection sites and enter the subcortical WM underneath the cerebral cortex, in the rat named the forceps minor of the CC (Fig. $3 A, B$ ). Although this name would suggest that these fibers cross the midline to the contralateral hemisphere (and a large contingent of fibers indeed take this course), a majority of the fibers that enter the subcortical WM stay ipsilaterally and travel to the striatum, thalamus, hypothalamus, and brainstem. Therefore, axons split into two bundles (Fig. 3C,D): one passes to the contralateral cortex and the second is the cortical descending bundle and travels toward and enters the striatum. This bundle then divides into small fascicles that are embedded within the striatum (Fig. $3 E, F$ ). Axons from the different injection sites enter and travel in different regions of the striatum. As fibers travel caudally within these fascicles, some exit at specific points to terminate in the striatum. Others continue to the level of the anterior commissure, where they enter the forming main body of the internal capsule. Here, fibers move ventrally as they travel to the thalamus and brainstem (Fig. 3G). 

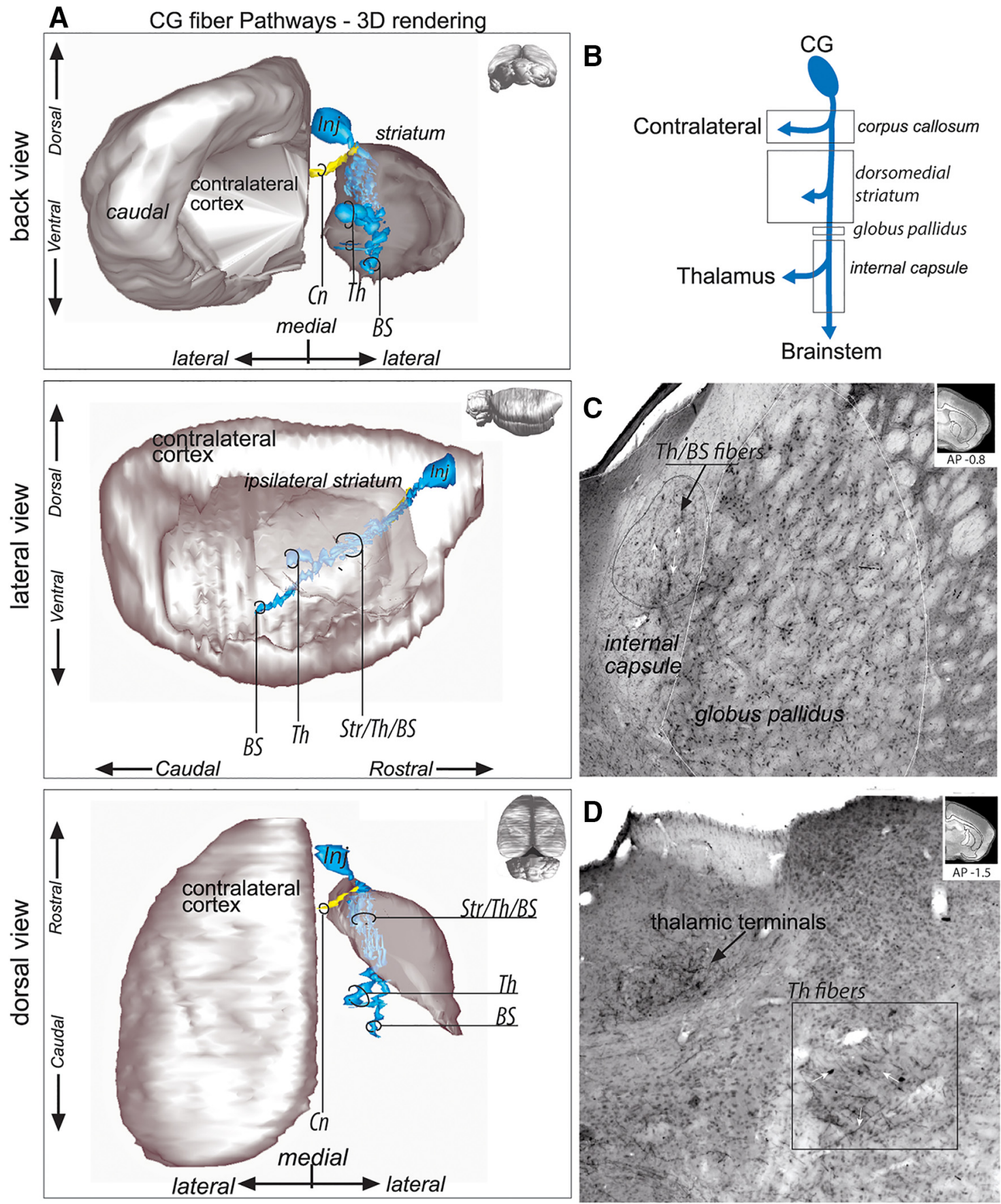

Figure 4. $\quad$ CG fiber pathways. $A, 3 D$ rendering of $C G$ fiber pathways. To better visualize the fiber bundles, the $3 D$ rendering is presented with the contralateral cortex and ipsilateral striatum after removal of the ipsilateral cortex from back coronal (top), lateral sagittal (middle), and dorsal horizontal (bottom) views. Note that axons traveling through the striatum to the thalamus and brainstem are intermixed and that two segregated thalamic fiber bundles could be identified. B, Schematic illustration of CG bundle subdivisions. C, Photomicrograph showing CG fibers traveling posteriorly toward the thalamus and brainstem as a large bundle in the center of the internal capsule. Top right, Coronal section for orientation. D, Photomicrograph of the CG-thalamic labeled fibers and thalamic terminals. CG axons leave the internal capsule and travel to the thalamus in a large, sparse bundle. Top right, Coronal section for orientation. AP, Anterior-posterior distance from bregma; BS, brainstem; Cn, contralateral fibers; Inj, injection site; Str/Th/BS, striatum/thalamus/brainstem; Th, thalamus; Th/BS, thalamus/brainstem.

\section{Cingulate cortex}

Descending axons from the CG (Fig. 4A,B) enter the central part of the forceps minor of the $\mathrm{CC}$ and travel to the rostral portion of the dorsal striatum. Here, the bundle splits into fascicles that disperse throughout the medial striatum and travel posteriorly. Some of these axons terminate in the medial striatum and others descend toward the internal capsule. At this level in the striatum, CG axons traveling to the internal capsule and the striatum are intermixed. Descending fibers (some of which course through the medial edge of the globus pallidus) enter the internal capsule at its dorsal tip as it emerges anteriorly. As the fibers move caudally, they occupy the central part of the internal capsule. Posteriorly and ventrally, the bundle splits into two bundles (Fig. 4C,D): one exits the internal capsule to reach the thalamus and the second continues to descend to the hypothalamus and brainstem.

\section{PL cortex}

Unlike axons from the CG, descending axons from the PL (Fig. $5 A, B)$ enter the CC and immediately split into two bundles. Both 

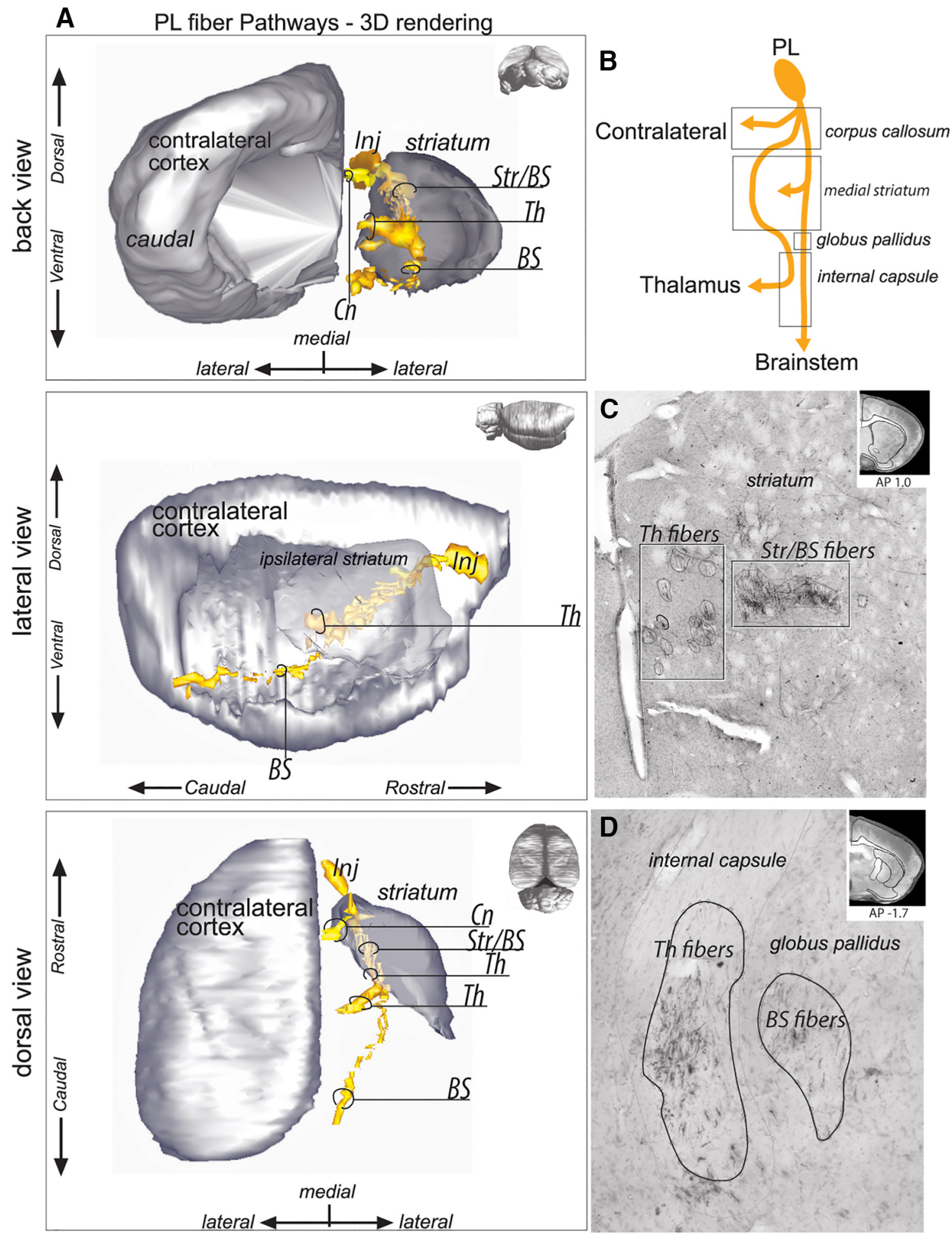

Figure 5. PL fiber pathways. $A, 3 D$ rendering of PL fiber pathways. To better visualize the fiber bundles, the $3 D$ rendering is presented with the contralateral cortex and ipsilateral striatum after removal of the ipsilateral cortex from back coronal (top), lateral sagittal (middle), and dorsal horizontal (bottom) views. Note that axons traveling through the striatum divide into a medial thalamic and a lateral striatal and brainstem projection. $B$, Schematic illustration of PL bundle subdivisions. C, Photomicrograph showing how the fascicles of PL-thalamic fibers are segregated from the PL-striatal and PL- brainstem fibers within the striatum. Top right, Coronal section for orientation. $D$, Photomicrograph of the PL-thalamic and PL-brainstem labeled fibers. The corticothalamic bundle exits the striatum to enter the internal capsule, whereas the cortico-brainstem bundle first crosses the globus pallidus before joining the internal capsule. Top right, Coronal section for orientation. AP, Anterior-posterior distance from bregma; BS, brainstem; Cn, contralateral fibers; Inj, injection site; Str/BS, striatum/brainstem; Th, thalamus.

bundles travel to the striatum. These two bundles enter the striatum dorsally and immediately form two adjacent but segregated groups of fascicles (Fig. $5 \mathrm{C}$ ). One bundle travels along the medial border of the striatum to join the internal capsule. As the fibers move caudally, they occupy the central part of the internal capsule ventral to CG fibers (Fig. 5D). Posteriorly, they leave the internal capsule to terminate in thalamus. The second bundle travels more laterally in the central striatum (Fig. 5C). A substan- 
A IL fiber Pathways - 3D rendering
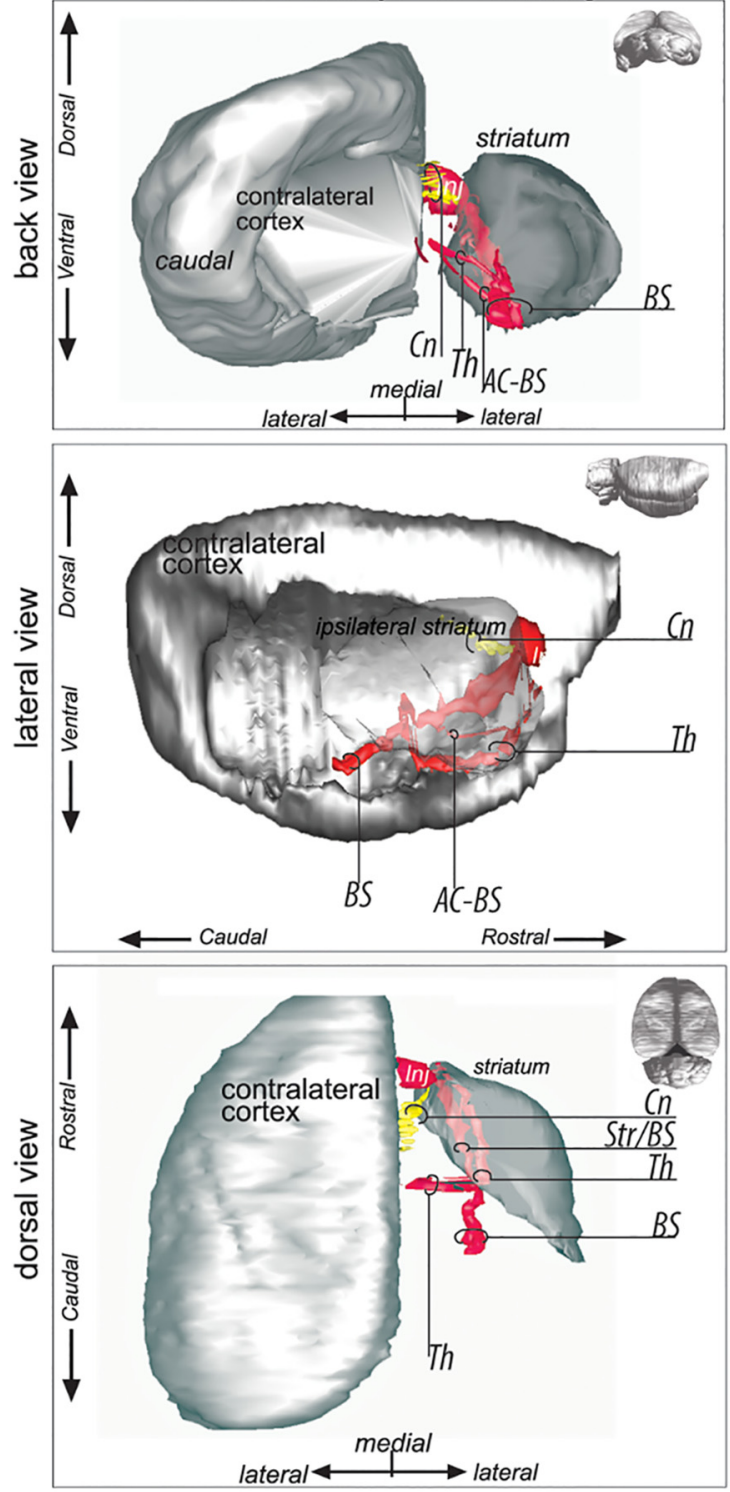

$B$
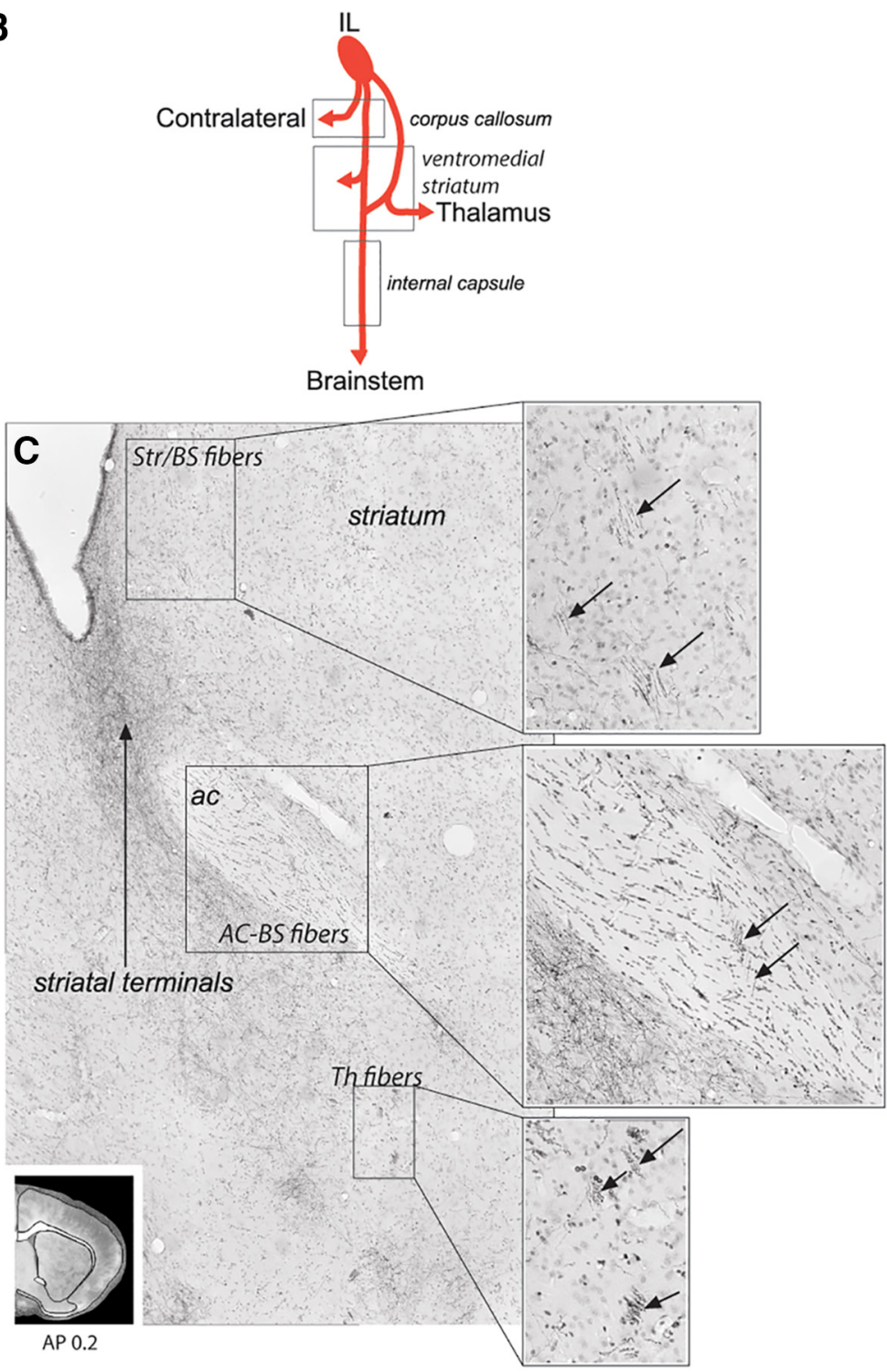

Figure 6. IL fiber pathways. $A, 3 D$ rendering of IL fiber pathways. To better visualize the fiber bundles, the 3D rendering is presented with the contralateral cortex and ipsilateral striatum after removal of the ipsilateral cortex from a back coronal (top), lateral sagittal (middle), and dorsal horizontal (bottom) view. Note the complexity of IL projections compared with the other cases. The IL-thalamic axons are segregated from the striatal/brainstem axons at the level of the injection site. Fibers bifurcate from the thalamic bundle to travel across the anterior commissure to the internal capsule. $\boldsymbol{B}$, Schematic illustration of IL bundle subdivisions. C, Photomicrograph showing three segregated bundles within the striatum: a brainstem bundle traveling across the striatum and the internal capsule and a thalamic bundle crossing the ventral striatum from which a third bundle deviates to travel within the anterior commissure to then merge with the main brainstem bundle. Bottom left, Coronal section for orientation. AC-BS, Brainstem fibers passing through the anterior commissure; AP, anterior-posterior distance from bregma; BS, brainstem; Cn, contralateral fibers; Inj, injection site; Str/BS, striatum/brainstem; Th, thalamus.

tial part of the fibers in this second group terminate in the central striatum. The remaining fibers (Fig. 5D) descend, taking first a ventral course to subsequently cross the rostral globus pallidus and join the ventral portion of the internal capsule to descend to the brainstem.

\section{Infralimbic cortex}

Descending axons from the IL (Fig. $6 A, B$ ) form two segregated bundles adjacent to the injection site. The first bundle crosses the ventromedial forceps minor of the CC and enters the ventromedial striatum, where it splits into fascicles. These fascicles travel caudally within a narrow portion of the medial striatum. IL fascicles traveling to different destinations (including the striatum and the brainstem) are intermixed at this level (Fig. 6C). Some of these IL axons terminate in the medial striatum. Others descend and enter the internal capsule as it emerges anteriorly. They travel in the most ventral part of the internal capsule to reach the brainstem.

The second bundle does not travel through the CC when leaving IL; instead, it continues ventrally through the cortex to enter the anterior nucleus accumbens, where it splits into fascicles. In the ventral striatum, fibers split further into two smaller bundles. One of these travels posteriorly within the anterior commissure (Fig. $6 C$ ), enters the ventral internal capsule, and descends to the brainstem. The second bundle travels ventrally in the striatum (Fig. 6C), exiting at the level of the anterior commissure decussation to finally terminate in thalamus. 

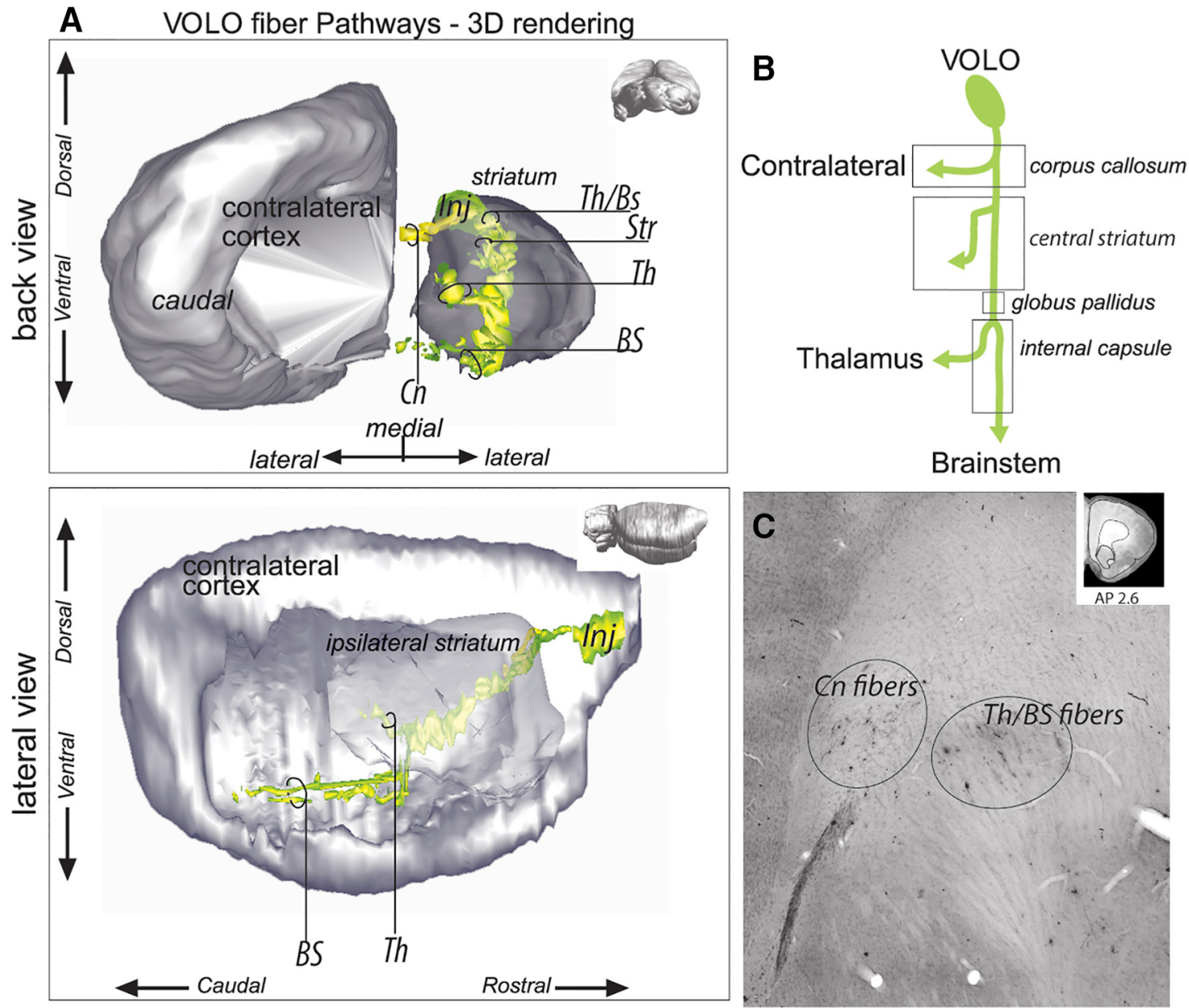

\section{Brainstem}
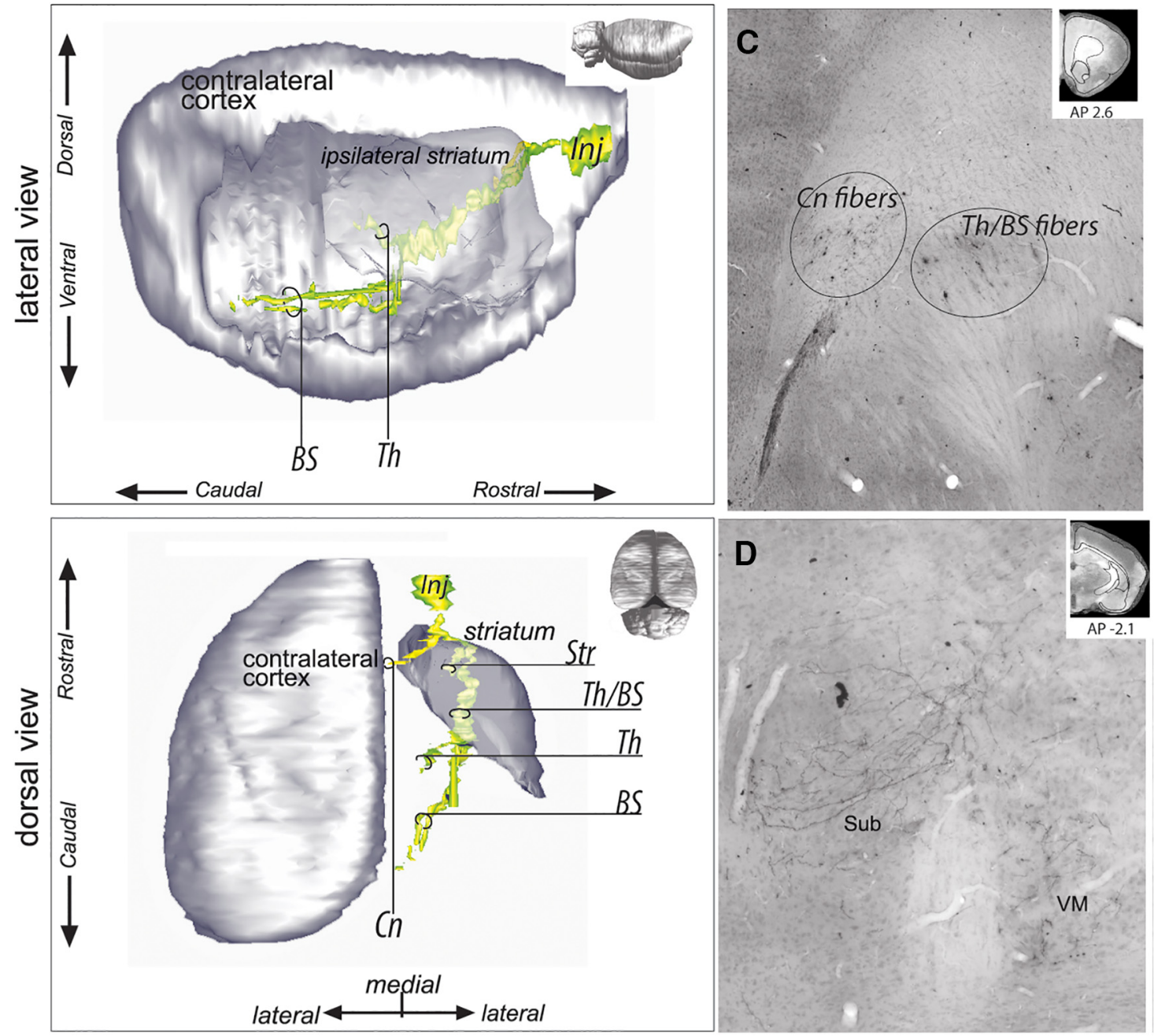

Figure 7. V0LO fiber pathways. $A, 3 \mathrm{D}$ rendering of $\mathrm{V} 0 \mathrm{~L} 0$ fiber pathways. To better visualize the fiber bundles, the $3 \mathrm{D}$ rendering is presented with the contralateral cortex and ipsilateral striatum after removal of the ipsilateral cortex from a back coronal (top), lateral sagittal (middle), and dorsal horizontal (bottom) view. B, Schematic illustration of VOLO bundle subdivisions. C, Photomicrograph showing the forceps minor of the $\mathrm{CC}$, in which axons traveling to the contralateral side and to the thalamus/brainstem segregate. Top right, Coronal section for orientation. $\mathbf{D}$, Photomicrographs of the VOLO-thalamic terminals located in the submedius and ventromedian thalamus. Top right, Coronal section for orientation. AP, Anterior-posterior distance from bregma; BS, brainstem; Cn, contralateral fibers; Inj, injection site; Str, striatum; Sub, submedius thalamic nucleus; Th, thalamus; Th/BS, thalamus/brainstem; VM, ventromedian thalamic nucleus.

\section{Ventral/lateral orbital cortex}

Descending axons from the VOLO enter the lateral forceps minor of the CC (Fig. $7 A-C$ ) and travel to the anterior dorsolateral striatum. There, like PL fibers, VOLO fibers form two segregated, adjacent groups of fascicles. The first travels medially and terminates in the central striatum. The second group of labeled fasci- cles continues across the striatum and the anterior globus pallidus to reach the central lateral part of the internal capsule. There, they split into two small, segregated groups of fibers, one that travels medially in the capsule to reach the thalamus (Fig. $7 D$ ) and a second one that continues ventrally to the hypothalamus and the brainstem. 


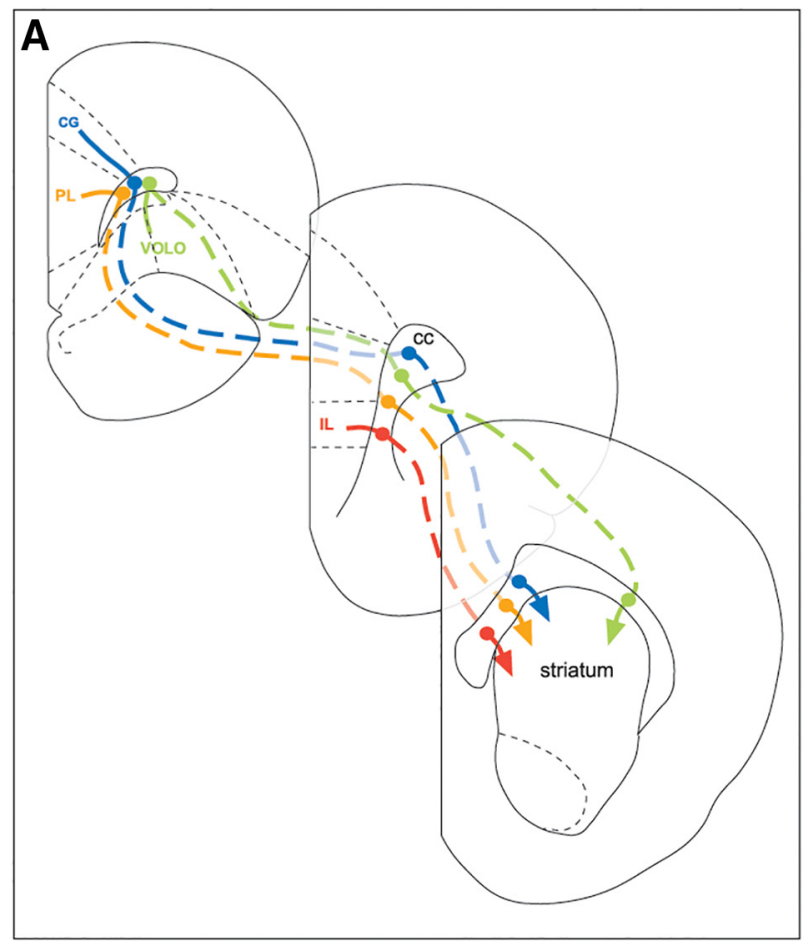

\section{C sagittal view}

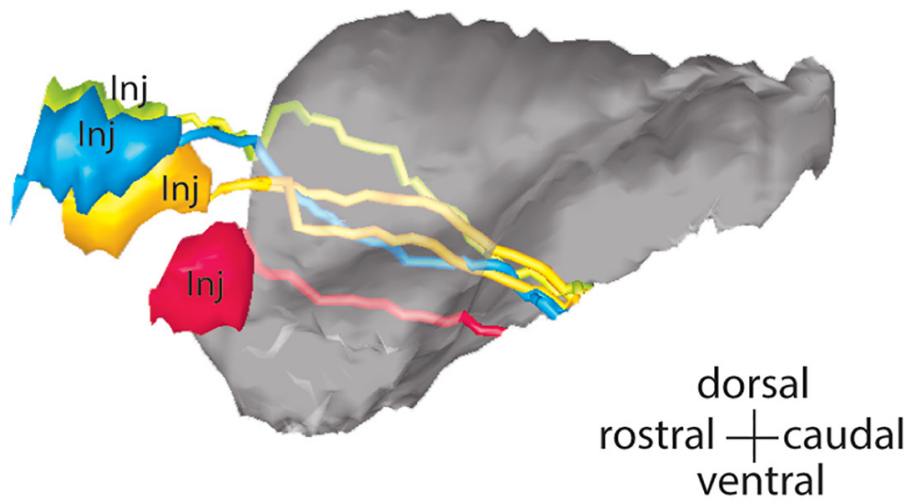

B
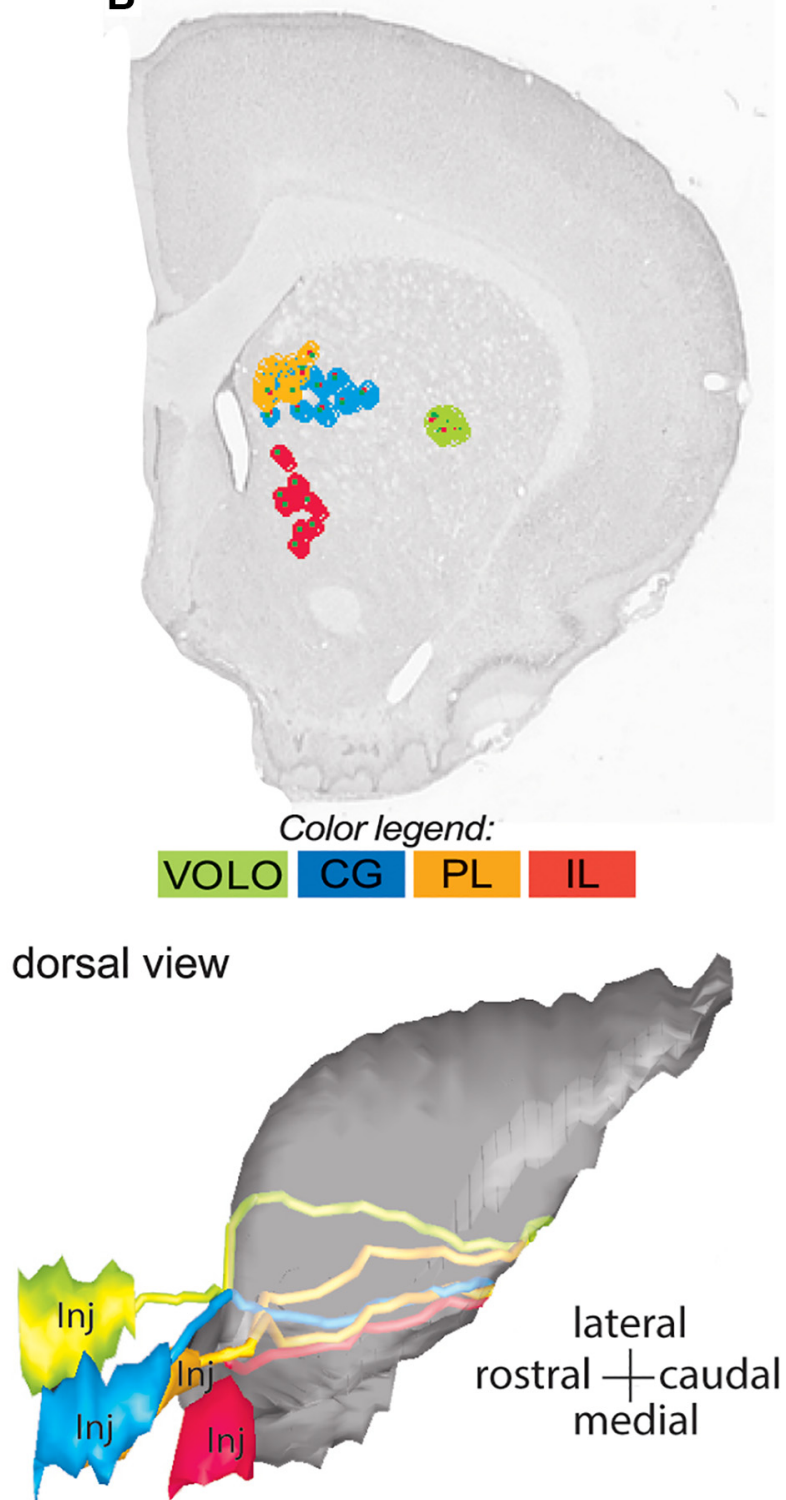

\section{D}

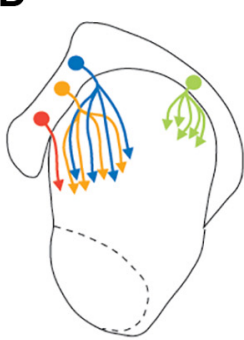

AP: 1.7

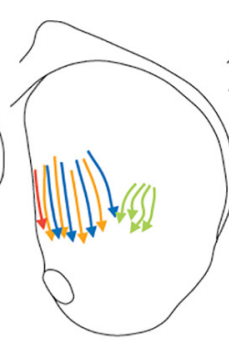

AP: 0.70

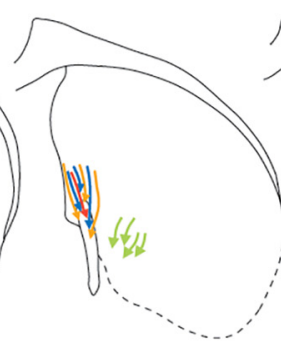

AP: -0.26

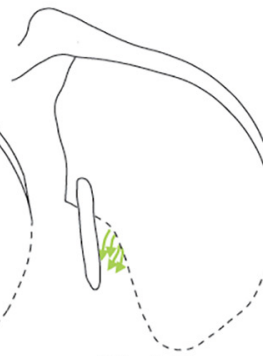

AP: -0.30

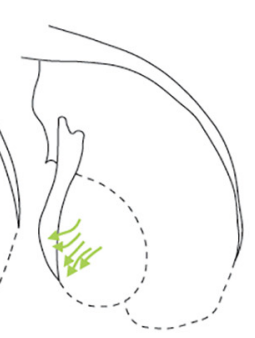

AP: -0.92

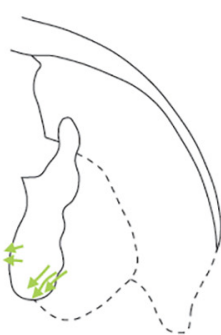

AP: -1.30

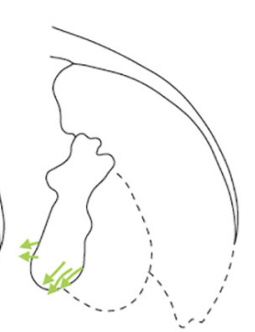

AP: -1.40

Figure 8. Topographical organization of OCIP descending pathways. A, Schematic of coronal sections illustrating topography of OCIP bundles within the CC/subcortical WM from the injection site (top left section) to the location where they enter the striatum (bottom right section). Note that the four bundles remain segregated and topographically organized according to the position of structures within PFC. B Coronal section showing the organization of the labeled OCIP fascicles in the rostral striatum. OCIP bundles descending to the thalamus and brainstem are well segregated within this structure except for $\mathrm{CG}$ and PL, which are partly intermixed. C, Sagittal (left) and dorsal (right) 3D views of the striatum showing the topography of 0 CIP pathways through this structure. $D$, Schematics of coronal sections illustrating 0 CIP bundle organization from the location where they enter the striatum to where they enter the internal capsule. Note that the four bundles remain segregated and topographically organized according to the position of structures within PFC, with IL, PL, and CG medial and VOLO lateral. AP, Anterior-posterior distance from bregma; Inj, injection site. 
Rules of organization of OCIP bundles All OCIP fibers leaving the cortex to travel to the striatum and other targets have to traverse the CC (Fig. 8A). However, the location of fibers within the $\mathrm{CC}$ reflects their cortical region of origin. Fibers from VOLO travel in the lateral CC, whereas axons from the medial PFC travel in the medial CC. CG fibers are dorsal to IL fibers, with axons from PL positioned in between. This reflects their medial-lateral and dorsal-ventral cortical positions.

There is no compact WM bundle that connects the CC with the internal capsule. Rather, axons from OCIP structures travel within the WM fascicles embedded in the striatum to reach the internal capsule. Nonetheless, the OCIP fibers do maintain their topography as they pass through the striatum to reach the thalamus and brainstem (Fig. 8B-D). Therefore, medial PFC fibers travel medially within the striatum to VOLO fibers. There is also a general dorsal-ventral topography, but with some overlap. Interestingly, IL fascicles travel within a narrow portion of the ventromedial striatum and are not intermixed with other OCIP bundles. In contrast, PL and CG fibers are spread over a large part of the medial half of the striatum and are partly intermixed. This topography is consistent across all of the individual cases (Fig. 9).

Although axons from different OCIP regions overlap extensively through the internal capsule, there is a discernible topography (Fig. 10). Axons from IL, PL, and CG enter the most rostral portion of the anterior internal capsule and separate according to dorsal-ventral position. Axons from IL travel ventrally within the rostral internal capsule, those from CG travel dorsally within the rostral internal capsule, and those from PL travel between those from IL and CG. In contrast, VOLO axons are not present at the most rostral portion of the internal capsule. Instead, at the level of the anterior globus pallidus, fibers from VOLO enter the internal capsule laterally. There, they merge with axons from CG, PL, and IL to travel caudally. At more caudal levels, OCIP axons have a medial to lateral topography in the ventral part of the internal capsule.

\section{Discussion}

Overview

Experiments in rats provide essential information on the mechanisms of brain function, including WM composition and perturbations. Descending PFC fibers in primates form a well defined ALIC, but the specific locations and organization of these fibers in rats is unknown. We addressed this gap by analyzing descending fibers from IL, PL, CG, and VOLO. Descending PFC fibers form WM fascicles embedded within the striatum. These bundles are arranged
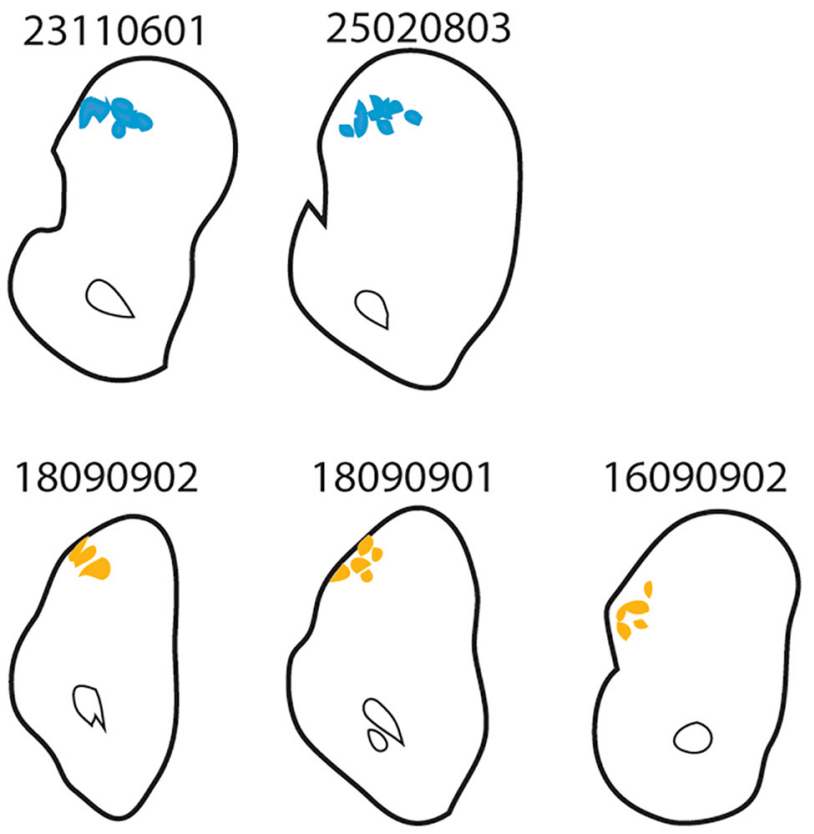

Figure 9. Position of descending fibers in each individual OCIP case. Case numbers are shown directly above coronal slices of the striatum (level as in Fig. 8B). Descending fibers are colored. Where possible, striatal fibers were excluded. Note the similarity across cases within a given brain region (fibers ventral to the anterior commissure were also observed in IL case 93283, but they were not dense enough to be considered a bundle).
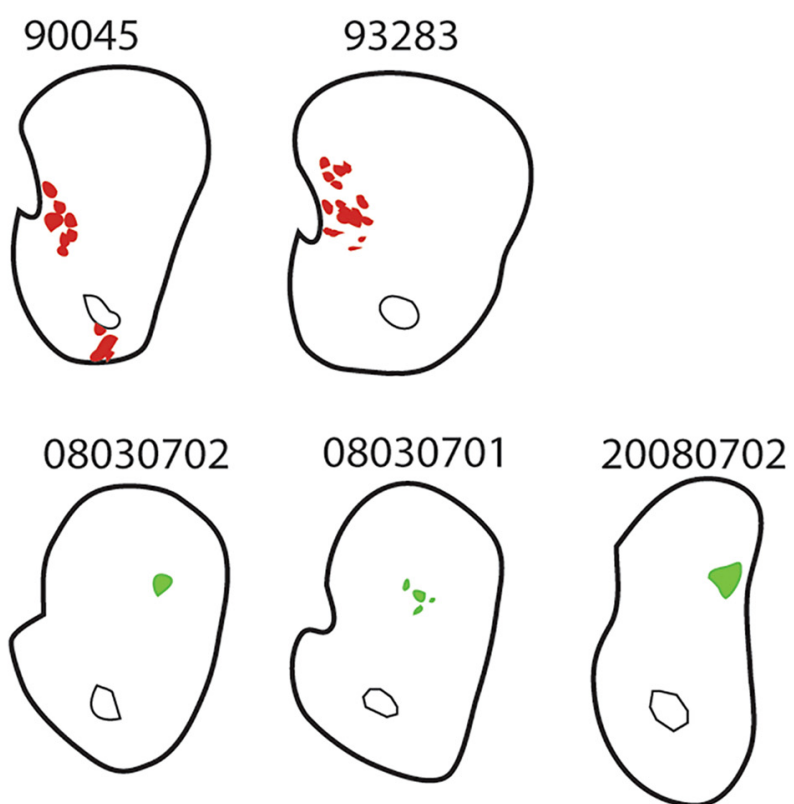

topographically according to origin and target location and contain descending projections not only to the striatum, but also to the thalamus and brainstem. They can therefore be viewed as the ALIC homolog in the rat; we expect that future experiments will identify the ascending fibers present in these fascicles as well. Mapping these projections allows us to more precisely identify the fibers affected by experimental manipulations of the striatum, including HFS, pharmacological inactivation, and slice physiology. Therefore, understanding WM homologies across humans, nonhuman primates, and rodents allows us to link the precision of nonhuman animal models with the neural abnormalities and treatments identified in human psychiatric disorders. 


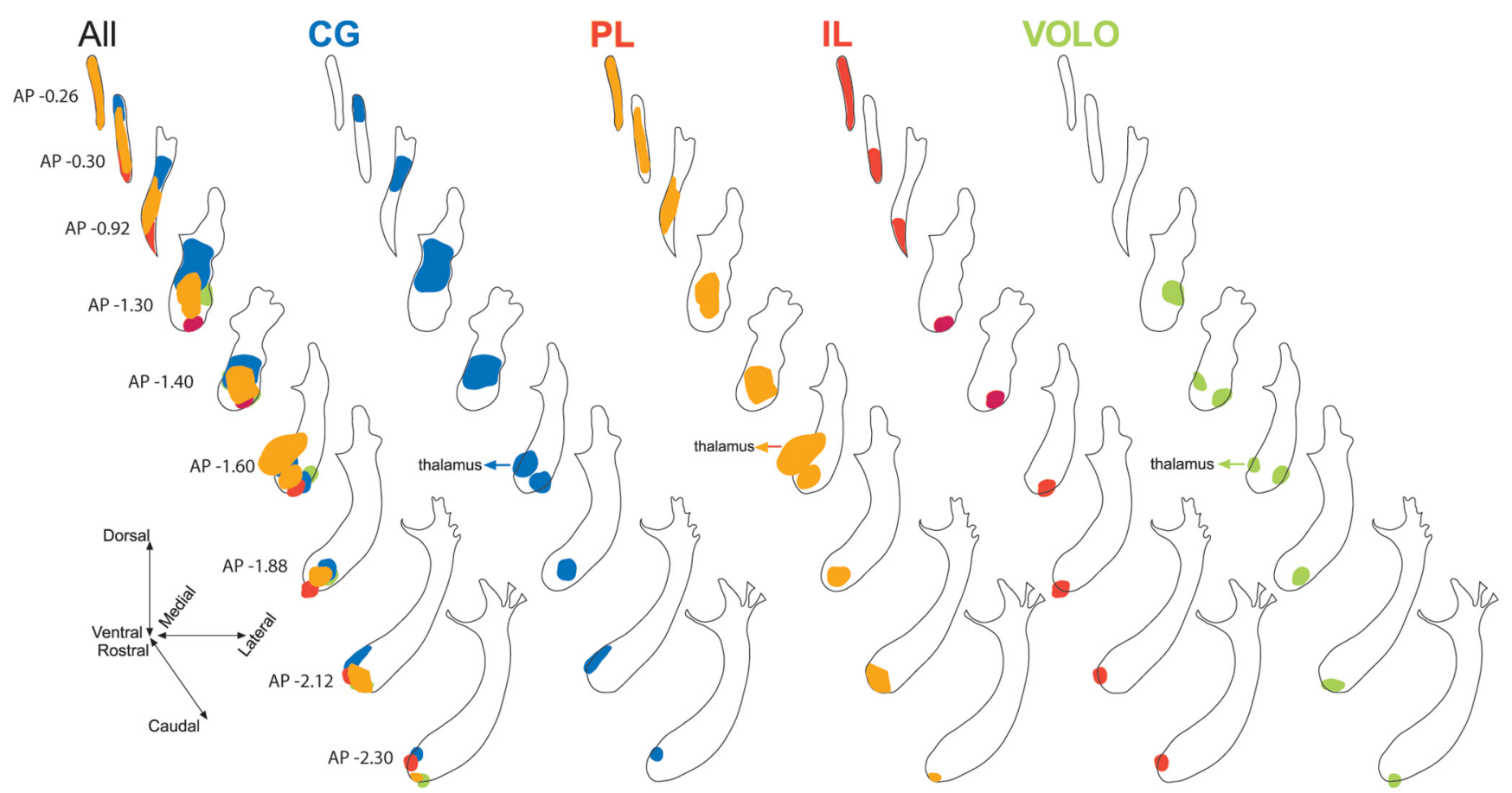

Figure 10. OCIP fibers in the internal capsule. Shown are coronal schematics of the internal capsule with delineations of the position and extent of OCIP fibers while traveling caudally. The left schematic includes all OCIP cases to show their relative positions within this WM. Note that OCIP bundles have a rough topographic organization throughout the internal capsule. AP, Anteriorposterior distance from bregma.

\section{Color legend:}
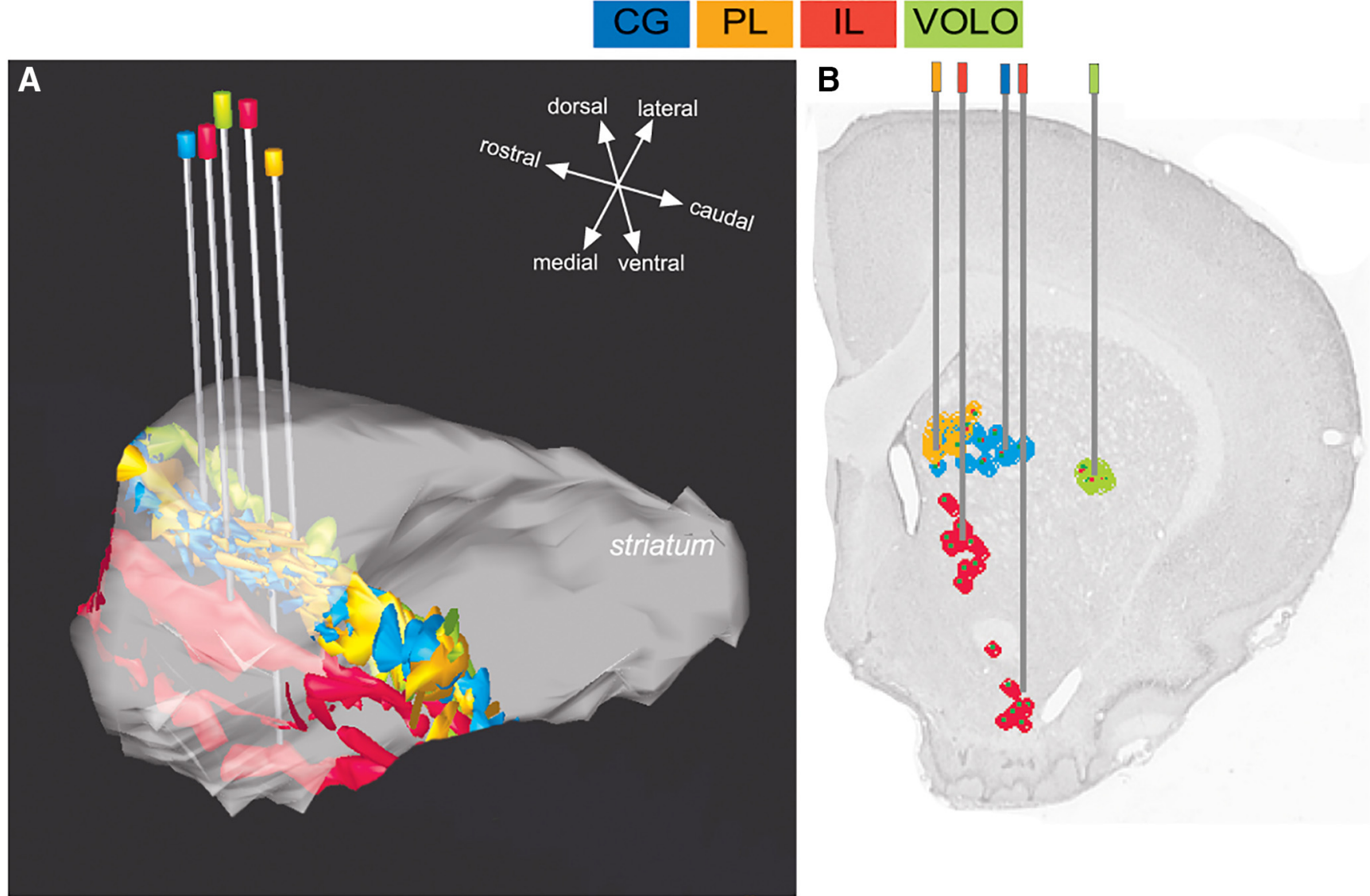

Figure 11. Modeled DBS electrodes at a striatal target. Electrodes are shown embedded in the different 0 CIP fascicles within the striatum illustrated $(\boldsymbol{A})$ in a $3 \mathrm{D}$ overview of the striatum with $0 \mathrm{CIP}$ bundles and on a coronal section with descending OCIP fibers $(\boldsymbol{B})$. Note that, because OCIP bundles are well segregated in the striatum, each electrode position illustrated captures a different set of 0 CIP fibers. 
A
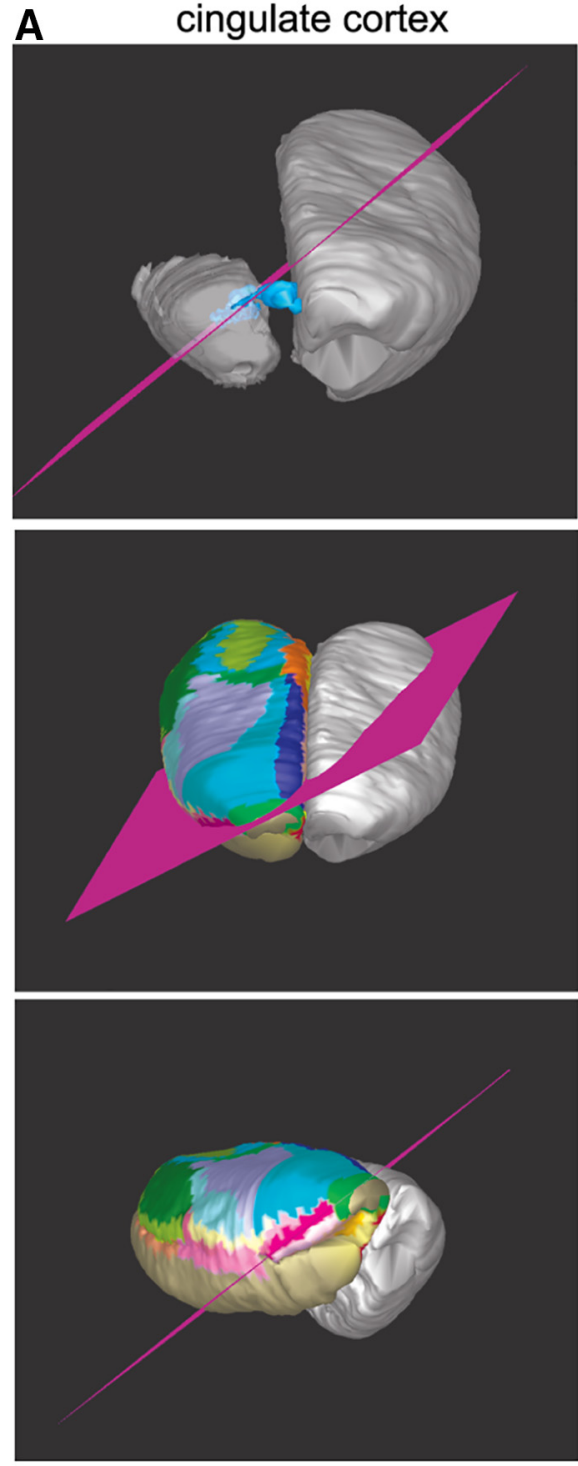

$\mathbf{B}+4.8$

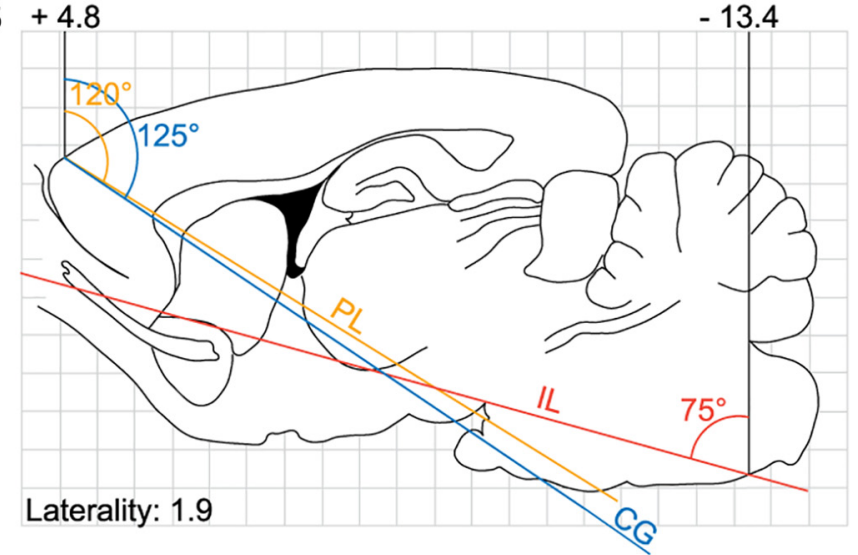

prelimbic cortex
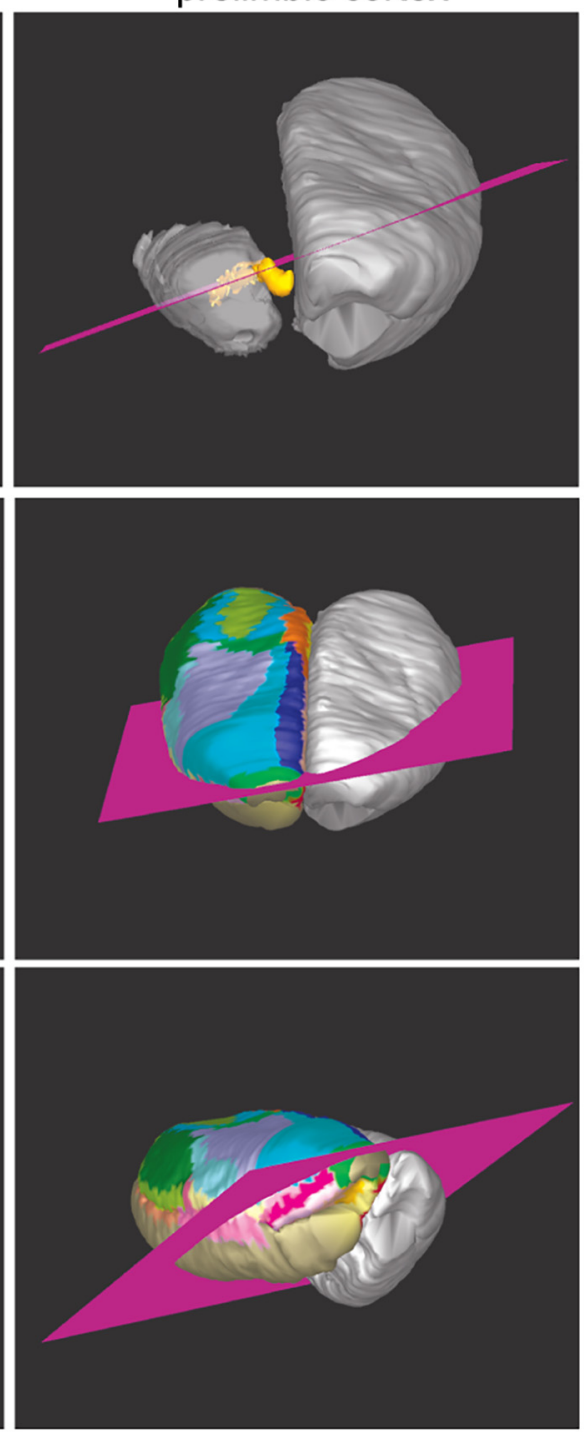

$6.3 \quad 4.13 .1$

infralimbic cortex
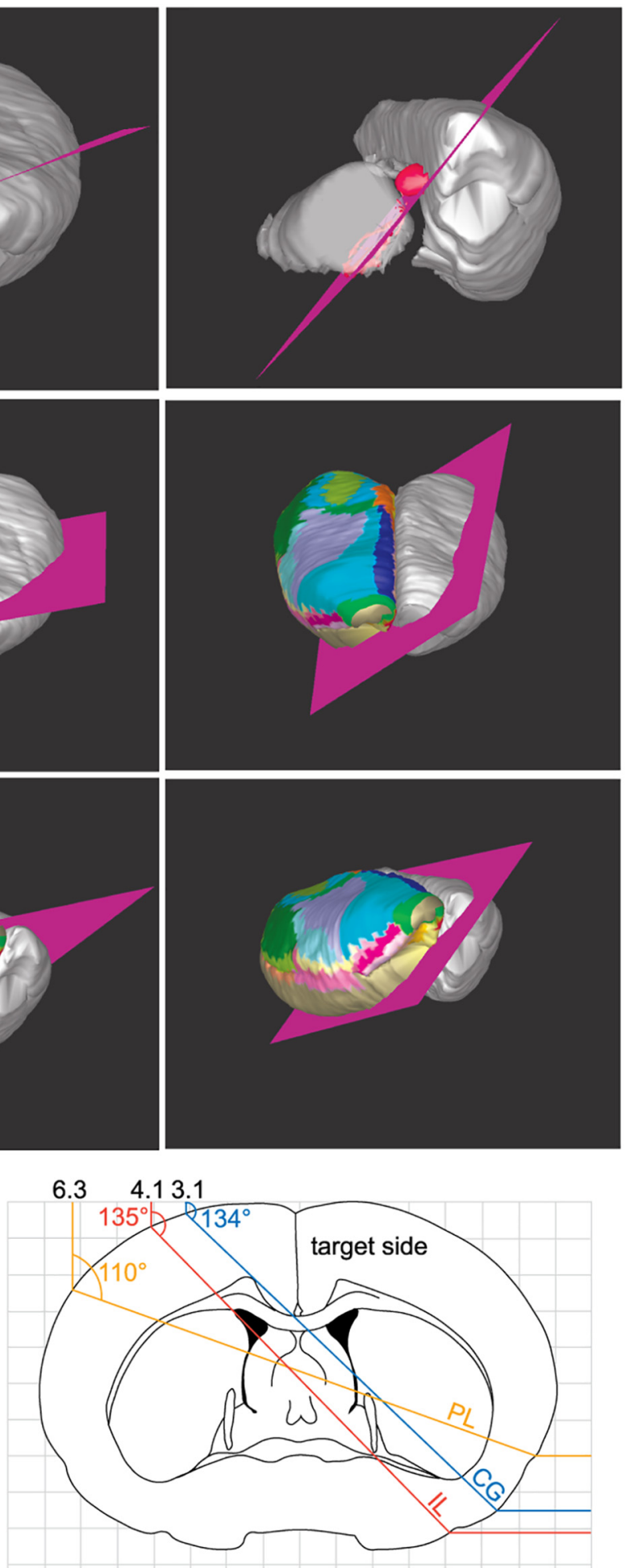

AP: -0.26

Figure 12. Model of the orientation of slice cuts to preserve the integrity of the CG (left), PL (middle), and IL (right) projections to the thalamus. A, Suggested cuts follow the fibers from the injection site and along the bundles. To better visualize the orientation of the cut along the fibers, the cortex has been removed on the ipsilateral side. The bottom panels illustrate the general orientation of the cut on a whole rat brain. Colorful cortex (delineation of cortical areas) indicates the targeted side. B, Sagittal (left) and coronal (right) representations from the Paxinos and Watson (1986) atlas showing the angles of the cut and the stereotaxic coordinates calculated from the reference point bregma. AP, Anterior-posterior distance from bregma. 

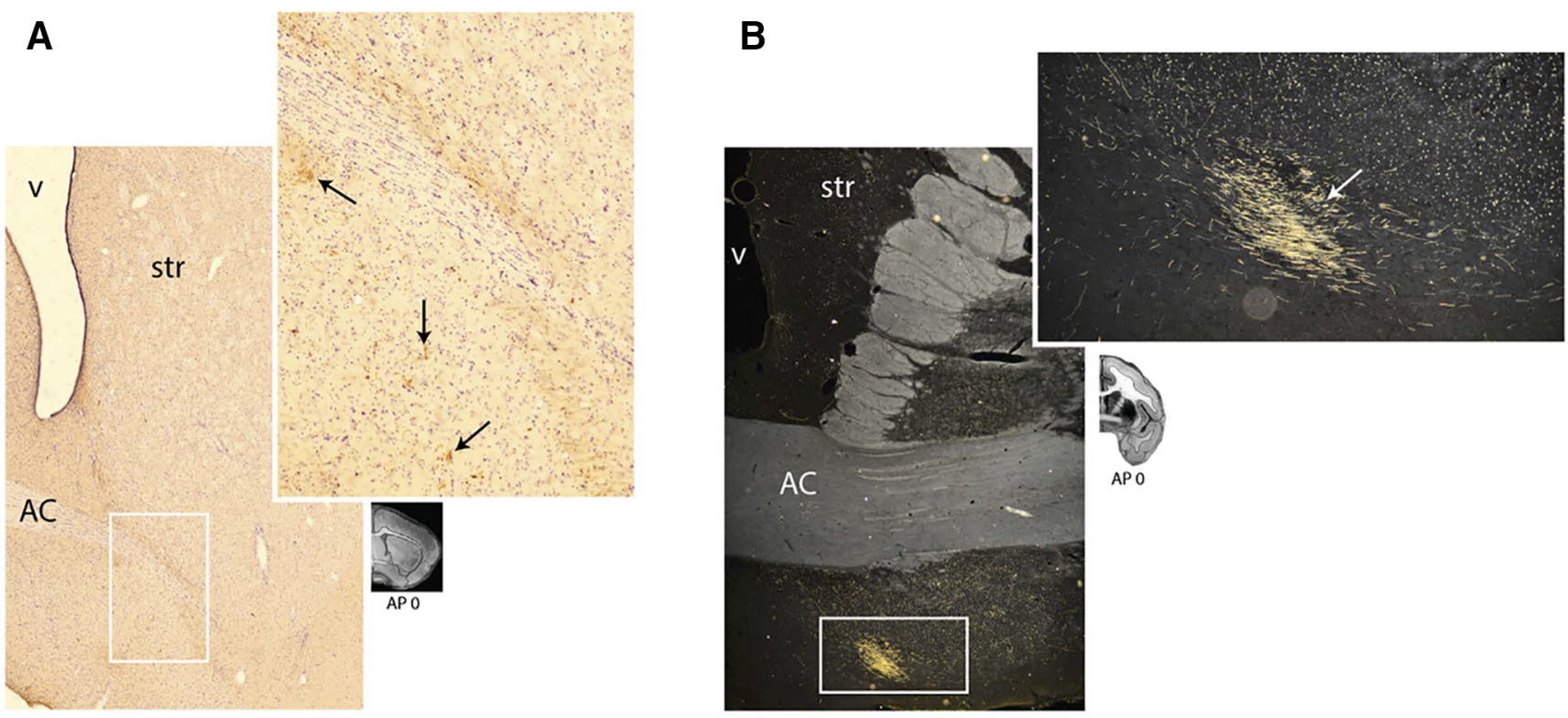

Figure 13. Similarities in the descending fibers from rat IL and monkey area 25 . A subset of fibers (arrows) from rat IL $(\boldsymbol{A})$ and monkey area $25(\boldsymbol{B})$ are both situated ventral to the anterior commissure at its decussation. They travel caudally to eventually join the internal capsule and terminate in the thalamus and brainstem. Coronal sections are shown for reference. AC, Anterior commissure; AP, anterior-posterior distance from bregma; str, striatum; $v$, ventricle.

\section{Descending projections in the rat}

PFC fibers leave the injection site, enter the subcortical WM, and split into two bundles: one uses the CC to cross to the contralateral hemisphere and the other descends into the striatum. Within the CC, fibers are arranged topographically: VOLO fibers travel laterally to IL, PL, and CG fibers and CG fibers travel dorsally to IL and PL fibers. Once in the striatum, descending fibers do not form an encapsulated bundle, but instead travel in fascicles embedded within the striatal gray matter. PFC fibers travel caudally and ventrally within these fascicles in a topographic manner: VOLO fibers are positioned laterally to medial PFC fibers and IL fibers are ventral to those from PL and CG. Many of these axons ultimately join the internal capsule. From there, some axons exit rostrally to terminate in the thalamus and others continue caudally and ventrally to the hypothalamus and the brainstem.

\section{Implications for studies of the function and connectivity of the striatum \\ HFS}

DBS for psychiatric disorders has targeted the nucleus accumbens, ALIC, and internal capsule (Sturm et al., 2003; Malone et al., 2009; Denys et al., 2010; Greenberg et al., 2010b). DBS mainly operates through activation of WM near the electrode (McIntyre and Hahn, 2010). Rodent models using HFS of the homologs of these targets are essential for testing the mechanisms of DBS (McCracken and Grace, 2007; Mundt et al., 2009; Rodriguez-Romaguera et al., 2012; Ahmari et al., 2013; Burguière et al., 2013; Hamani et al., 2014; Rea et al., 2014). Our results complement rodent DBS studies linking electrode locations with specific fibers. For example, the dorsal-ventral position of the DBS electrode in the rat internal capsule will affect IL, PL, CG, and VOLO fibers differentially (Fig. 10). Knowing this topography, it may be possible to stimulate particular components selectively. However, there is considerable overlap in fiber location in the internal capsule, so targeting different fiber populations may prove difficult. In contrast, the OCIP projections in the striatum are highly segregated.
Stimulation of the lateral ventral striatum will mainly affect VOLO fibers and spare those from IL, PL, and CG, which are limited to the medial striatum (Fig. 11). This may be particularly important because the medial PFC is central to emotional regulation and fear expression (Quirk and Beer, 2006; SotresBayon et al., 2006; Etkin et al., 2011).

A recent experiment explored the effects of HFS in different locations within the ventral striatum to modulate fear extinction in rats. Stimulating the centromedial striatum facilitated extinction; however, stimulating the ventrolateral striatum impaired extinction (Rodriguez-Romaguera et al., 2012). However, because local pharmacological inactivation did not alter extinction, HFS likely induced behavioral changes via passing and terminating axons. Our maps, along with those from Mailly et al. (2013), show that terminals from IL, CG, PL, and VOLO are located near the centromedial target. Furthermore, IL-brainstem and IL-striatal fibers are situated near this target, but IL-thalamic fibers are present near the ventrolateral target. This distinction provides a possible anatomical substrate for the observed differential behavioral effects of stimulation.

\section{Reversible pharmacological inactivation}

Reversible pharmacological inactivation of specific striatal regions allows researchers to probe the mechanisms driving behavior flexibly (Seamans and Phillips, 1994; Floresco et al., 1996; Packard and McGaugh, 1996; Kantak et al., 2001). However, some of these pharmacological agents, particularly lidocaine, also affect fibers of passage. Our results indicate that bundles containing fibers of passage are scattered throughout the rostral striatum and must be considered when designing experiments. Moreover, using different inactivation agents offers the possibility of comparing results when fibers of passage are affected or spared (Vassoler et al., 2013).

\section{Slice physiology}

Slice physiology is an experimental approach critical for understanding the synaptic mechanisms of the cortical projec- 
tions to the thalamus and brainstem (Lee et al., 2007; Cruikshank et al., 2012). The orientation of the cut is critical to preserve the complete set of connections. We found that, for preserving PL, IL, and CG descending fibers, the best planes are tilted toward the caudal and lateral edges of the brain (Fig. 12). However, due to the large medial-lateral distance that VOLO fibers covered, we could not identify a slice orientation that would preserve these axons.

\section{Automated connectivity}

Recently, the establishment of databases of rodent tracttracing results has allowed for large-scale analyses of neuroanatomical connectivity. The ensuing studies rely on signal detection of the fluorescent tract tracer to create large-scale connectivity matrices (Hunnicutt et al., 2014; Oh et al., 2014; Kuan et al., 2015; Quina et al., 2015; Hintiryan et al., 2016). However, these tracers label the entire axon, not just terminal fields. Although large WM tracts are segmented out of the resulting matrices, the small ALIC fascicles embedded within the striatum may generate a false positive. Therefore, our results highlight the necessity of closer examination of such automated connectivity results within the striatum.

\section{ALIC across species}

Here, we identify the organization of the rat ALIC and thus can compare that with the nonhuman primate (Lehman et al., 2011). In contrast to the interest in gray matter comparisons, WM homologies have been largely ignored. However, based on the implications for experimental methods described above, understanding the architecture of rodent WM is critical for several reasons. First, such maps are necessary to perform HFS, inactivation, slice physiology, and automated studies of connectivity accurately. Second, understanding WM homologies adds critical data to the problem of using rodents to probe the neurobiological mechanisms of normal and abnormal brain function in humans. Many psychiatric disorders have been linked to abnormalities in prefrontal projections to subcortical targets and associated WM bundles (Alexopoulos et al., 2002; Tekin and Cummings, 2002; Szeszko et al., 2005; Volkow et al., 2011a; Haber and Heilbronner, 2013). Therefore, understanding the WM homologs of these PFCsubcortical circuits will aid the study of neurobiological abnormalities in rodents.

The major difference between the rat and primate ALIC is that most of the primate ALIC is well encapsulated (although a large number of fascicles embedded within the primate striatum are part of the ALIC; Lehman et al., 2011), whereas the entire rat ALIC consists of fascicles. Furthermore, for rats, as described above, medial PFC fibers travel medially to lateral PFC fibers. However, for monkeys, this axis is transformed into a dorsal-ventral one: medial vPFC fibers travel ventrally to lateral vPFC fibers (Lehman et al., 2011).

Nonetheless, both the rat and primate ALIC are organized topographically according to origin and target location and key elements of this topography are maintained across species. For example, a subset of rat IL projections to the thalamus do not pass through internal capsule, but rather remain in a ventral position in the region of the medial forebrain bundle. In the monkey, the descending fibers from area 25 also remain separate from the internal capsule, traveling instead in fascicles embedded in the ventral striatum and ventral to the anterior commissure, also in the area of the medial forebrain bundle (Fig. 13).
Previously, we identified the primate cortical homologs to different regions in the rat OCIP based on connectivity with conserved features of the striatum. We established that, as was described previously (Ongür and Price, 2000; Wise, 2008; Vogt and Paxinos, 2014), IL in rodents and area 25 in primates are homologous (Heilbronner et al., 2016). Like their terminal fields within the striatum, IL and area 25 descending fiber bundles are organized in a similar way across species. Similarly, medial versus lateral orbitofrontal cortices and portions of the dorsal ACC are likely homologs based on their striatal connections. Fibers from these rat OCIP areas are organized topographically. Importantly, axons from the comparable areas in primates are also organized topographically. Our results further emphasize the homology between these cortical areas across species. In summary, the results presented here, when combined with our previous work (Lehman et al., 2011; Jbabdi et al., 2013; Heilbronner et al., 2016), allow us to translate both WM and gray matter results from rodents to nonhuman primates and, ultimately, to humans.

\section{References}

Ahmari SE, Spellman T, Douglass NL, Kheirbek MA, Simpson HB, Deisseroth K, Gordon JA, Hen R (2013) Repeated cortico-striatal stimulation generates persistent OCD-like behavior. Science 340:1234-1239. CrossRef Medline

Alexopoulos GS, Kiosses DN, Choi SJ, Murphy CF, Lim KO (2002) Frontal white matter microstructure and treatment response of late-life depression: a preliminary study. Am J Psychiatry 159:1929-1932. CrossRef Medline

Berendse HW, Galisde-de Graaf Y, Groenewegen HJ (1992) Topographical organization and relationship with ventral striatal compartments of prefrontal corticostriatal projections in the rat. J Comp Neurol 316:314-347. CrossRef Medline

Burguière E, Monteiro P, Feng G, Graybiel AM (2013) Optogenetic stimulation of lateral orbitofronto-striatal pathway suppresses compulsive behaviors. Science 340:1243-1246. CrossRef Medline

Cenci MA, Whishaw IQ, Schallert T (2002) Animal models of neurological deficits: how relevant is the rat?. Nat Rev Neurosci 3:574-579. CrossRef Medline

Cosgrove VE, Kelsoe JR, Suppes T (2016) Toward a valid animal model of bipolar disorder: how the research domain criteria help bridge the clinical-basic science divide. Biol Psychiatry 79:62-70. CrossRef Medline

Crawley JN (1985) Exploratory behavior models of anxiety in mice. Neurosci Biobehav Rev 9:37-44. CrossRef Medline

Cruikshank SJ, Ahmed OJ, Stevens TR, Patrick SL, Gonzalez AN, Elmaleh M, Connors BW (2012) Thalamic control of layer 1 circuits in prefrontal cortex. J Neurosci 32:17813-17823. CrossRef Medline

Dalley JW, Cardinal RN, Robbins TW (2004) Prefrontal executive and cognitive functions in rodents: neural and neurochemical substrates. Neurosci Biobehav Rev 28:771-784. CrossRef Medline

Denys D, Mantione M, Figee M, van den Munckhof P, Koerselman F, Westenberg H, Bosch A, Schuurman R (2010) Deep brain stimulation of the nucleus accumbens for treatment-refractory obsessive-compulsive disorder. Arch Gen Psychiatry 67:1061-1068. CrossRef Medline

Duran FL, Hoexter MQ, Valente AA Jr, Miguel EC, Busatto GF (2009) Association between symptom severity and internal capsule volume in obsessive-compulsive disorder. Neurosci Lett 452:68-71. CrossRef Medline

Etkin A, Egner T, Kalisch R (2011) Emotional processing in anterior cingulate and medial prefrontal cortex. Trends Cogn Sci 15:85-93. CrossRef Medline

Floresco SB, Seamans JK, Phillips AG (1996) Differential effects of lidocaine infusions into the ventral CA1/subiculum or the nucleus accumbens on the acquisition and retention of spatial information. Behav Brain Res 81:163-171. CrossRef Medline

Greenberg BD, Rauch SL, Haber SN (2010a) Invasive circuitry-based neurotherapeutics: stereotactic ablation and deep brain stimulation for OCD. Neuropsychopharmacology 35:317-336. CrossRef Medline

Greenberg BD, Gabriels LA, Malone DA Jr, Rezai AR, Friehs GM, Okun MS, Shapira NA, Foote KD, Cosyns PR, Kubu CS, Malloy PF, Salloway SP, Giftakis JE, Rise MT, Machado AG, Baker KB, Stypulkowski PH, Good- 
man WK, Rasmussen SA, Nuttin BJ (2010b) Deep brain stimulation of the ventral internal capsule/ventral striatum for obsessive-compulsive disorder: worldwide experience. Mol Psychiatry 15:64-79. CrossRef Medline

Haber SN, Behrens TE (2014) The neural network underlying incentivebased learning: implications for interpreting circuit disruptions in psychiatric disorders. Neuron 83:1019-1039. CrossRef Medline

Haber SN, Heilbronner SR (2013) Translational research in OCD: circuitry and mechanisms. Neuropsychopharmacology 38:252-253. CrossRef Medline

Hamani C, Amorim BO, Wheeler AL, Diwan M, Driesslein K, Covolan L, Butson CR, Nobrega JN (2014) Deep brain stimulation in rats: different targets induce similar antidepressant-like effects but influence different circuits. Neurobiol Dis 71:205-214. CrossRef Medline

Heidbreder CA, Groenewegen HJ (2003) The medial prefrontal cortex in the rat: evidence for a dorso-ventral distinction based upon functional and anatomical characteristics. Neurosci Biobehav Rev 27:555-579. CrossRef Medline

Heilbronner SR, Rodriguez-Romaguera J, Quirk GJ, Groenewegen HJ, Haber SN (2016) Circuit-based corticostriatal homologies between rat and primate. Biol Psychiatry 80:509-521. CrossRef Medline

Hintiryan H, Foster NN, Bowman I, Bay M, Song MY, Gou L, Yamashita S, Bienkowski MS, Zingg B, Zhu M, Yang XW, Shih JC, Toga AW, Dong HW (2016) The mouse cortico-striatal projectome. Nat Neurosci 19:11001114. CrossRef Medline

Hunnicutt BJ, Long BR, Kusefoglu D, Gertz KJ, Zhong H, Mao T (2014) A comprehensive thalamocortical projection map at the mesoscopic level. Nat Neurosci 17:1276-1285. CrossRef Medline

Jbabdi S, Lehman JF, Haber SN, Behrens TE (2013) Human and monkey ventral prefrontal fibers use the same organizational principles to reach their targets: tracing versus tractography. J Neurosci 33:3190-3201. CrossRef Medline

Jia Z, Huang X, Wu Q, Zhang T, Lui S, Zhang J, Amatya N, Kuang W, Chan RC, Kemp GJ, Mechelli A, Gong Q (2010) High-field magnetic resonance imaging of suicidality in patients with major depressive disorder. Am J Psychiatry 167:1381-1390. CrossRef Medline

Kantak KM, Green-Jordan K, Valencia E, Kremin T, Eichenbaum HB (2001) Cognitive task performance after lidocaine-induced inactivation of different sites within the basolateral amygdala and dorsal striatum. Behav Neurosci 115:589-601. CrossRef Medline

Koch K, Reess TJ, Rus OG, Zimmer C, Zaudig M (2014) Diffusion tensor imaging (DTI) studies in patients with obsessive-compulsive disorder (OCD): a review. J Psychiatr Res 54:26-35. CrossRef Medline

Kremer JR, Mastronarde DN, McIntosh JR (1996) Computer visualization of three-dimensional image data using IMOD. J Struct Biol 116:71-76. CrossRef Medline

Kuan L, Li Y, Lau C, Feng D, Bernard A, Sunkin SM, Zeng H, Dang C, Hawrylycz M, Ng L (2015) Neuroinformatics of the Allen Mouse Brain Connectivity Atlas. Methods 73:4-17. CrossRef Medline

Lang DJ, Khorram B, Goghari VM, Kopala LC, Vandorpe RA, Rui Q, Smith GN, Honer WG (2006) Reduced anterior internal capsule and thalamic volumes in first-episode psychosis. Schizophr Res 87:89-99. CrossRef Medline

Lee CM, Chang WC, Chang KB, Shyu BC (2007) Synaptic organization and input-specific short-term plasticity in anterior cingulate cortical neurons with intact thalamic inputs. Eur J Neurosci 25:2847-2861. CrossRef Medline

Lehman JF, Greenberg BD, McIntyre CC, Rasmussen SA, Haber SN (2011) Rules ventral prefrontal cortical axons use to reach their targets: implications for diffusion tensor imaging tractography and deep brain stimulation for psychiatric illness. J Neurosci 31:10392-10402. CrossRef Medline

Mailly P, Haber SN, Groenewegen HJ, Deniau JM (2010) A 3D multi-modal and multi-dimensional digital brain model as a framework for data sharing. J Neurosci Methods 194:56-63. CrossRef Medline

Mailly P, Aliane V, Groenewegen HJ, Haber SN, Deniau JM (2013) The rat prefrontostriatal system analyzed in 3D: evidence for multiple interacting functional units. J Neurosci 33:5718-5727. CrossRef Medline

Malone DA Jr, Dougherty DD, Rezai AR, Carpenter LL, Friehs GM, Eskandar EN, Rauch SL, Rasmussen SA, Machado AG, Kubu CS, Tyrka AR, Price LH, Stypulkowski PH, Giftakis JE, Rise MT, Malloy PF, Salloway SP, Greenberg BD (2009) Deep brain stimulation of the ventral capsule/ ventral striatum for treatment-resistant depression. Biol Psychiatry 65: 267-275. CrossRef Medline

Mayberg HS, Brannan SK, Mahurin RK, Jerabek PA, Brickman JS, Tekell JL, Silva JA, McGinnis S, Glass TG, Martin CC, Fox PT (1997) Cingulate function in depression: a potential predictor of treatment response. Neuroreport 8:1057-1061. CrossRef Medline

McCracken CB, Grace AA (2007) High-frequency deep brain stimulation of the nucleus accumbens region suppresses neuronal activity and selectively modulates afferent drive in rat orbitofrontal cortex in vivo. J Neurosci 27:12601-12610. CrossRef Medline

McIntyre CC, Hahn PJ (2010) Network perspectives on the mechanisms of deep brain stimulation. Neurobiol Dis 38:329-337. CrossRef Medline

Milad MR, Quirk GJ (2012) Fear extinction as a model for translational neuroscience: ten years of progress. Annu Rev Psychol 63:129-151. CrossRef Medline

Mundt A, Klein J, Joel D, Heinz A, Djodari-Irani A, Harnack D, Kupsch A, Orawa H, Juckel G, Morgenstern R, Winter C (2009) High-frequency stimulation of the nucleus accumbens core and shell reduces quinpiroleinduced compulsive checking in rats. Eur J Neurosci 29:2401-2412. CrossRef Medline

Nakamae T, Narumoto J, Sakai Y, Nishida S, Yamada K, Nishimura T, Fukui K (2011) Diffusion tensor imaging and tract-based spatial statistics in obsessive-compulsive disorder. J Psychiatr Res 45:687-690. CrossRef Medline

Oh SW et al. (2014) A mesoscale connectome of the mouse brain. Nature 508:207-214. CrossRef Medline

Ongür D, Price JL (2000) The organization of networks within the orbital and medial prefrontal cortex of rats, monkeys and humans. Cereb Cortex 10:206-219. CrossRef Medline

Packard MG, McGaugh JL (1996) Inactivation of hippocampus or caudate nucleus with lidocaine differentially affects expression of place and response learning. Neurobiol Learn Mem 65:65-72. CrossRef Medline

Paxinos G, Watson C (1986) In: The rat brain in stereotactic coordinates. New York: Academic

Quina LA, Tempest L, Ng L, Harris JA, Ferguson S, Jhou TC, Turner EE (2015) Efferent pathways of the mouse lateral habenula. J Comp Neurol 523:32-60. CrossRef Medline

Quirk GJ, Beer JS (2006) Prefrontal involvement in the regulation of emotion: convergence of rat and human studies. Curr Opin Neurobiol 16: 723-727. CrossRef Medline

Rea E, Rummel J, Schmidt TT, Hadar R, Heinz A, Mathé AA, Winter C (2014) Anti-anhedonic effect of deep brain stimulation of the prefrontal cortex and the dopaminergic reward system in a genetic rat model of depression: an intracranial self-stimulation paradigm study. Brain Stimul 7:21-28. CrossRef Medline

Rodriguez-Romaguera J, Do Monte FH, Quirk GJ (2012) Deep brain stimulation of the ventral striatum enhances extinction of conditioned fear. Proc Natl Acad Sci U S A 109:8764-8769. CrossRef Medline

Schilman EA, Uylings HB, Galis-de Graaf Y, Joel D, Groenewegen HJ (2008) The orbital cortex in rats topographically projects to central parts of the caudate-putamen complex. Neurosci Lett 432:40-45. CrossRef Medline

Seamans JK, Phillips AG (1994) Selective memory impairments produced by transient lidocaine-induced lesions of the nucleus accumbens in rats. Behav Neurosci 108:456-468. CrossRef Medline

Sotres-Bayon F, Cain CK, LeDoux JE (2006) Brain mechanisms of fear extinction: historical perspectives on the contribution of prefrontal cortex. Biol Psychiatry 60:329-336. CrossRef Medline

Sturm V, Lenartz D, Koulousakis A, Treuer H, Herholz K, Klein JC, Klosterkötter J (2003) The nucleus accumbens: a target for deep brain stimulation in obsessive-compulsive- and anxiety-disorders. J Chem Neuroanat 26:293-299. CrossRef Medline

Szeszko PR, Ardekani BA, Ashtari M, Malhotra AK, Robinson DG, Bilder RM, Lim KO (2005) White matter abnormalities in obsessivecompulsive disorder: a diffusion tensor imaging study. Arch Gen Psychiatry 62:782-790. CrossRef Medline

Tekin S, Cummings JL (2002) Frontal-subcortical neuronal circuits and clinical neuropsychiatry: an update. J Psychosom Res 53:647-654. CrossRef Medline

Togao O, Yoshiura T, Nakao T, Nabeyama M, Sanematsu H, Nakagawa A, Noguchi T, Hiwatashi A, Yamashita K, Nagao E, Kanba S, Honda H (2010) Regional gray and white matter volume abnormalities in 
obsessive-compulsive disorder: a voxel-based morphometry study. Psychiatry Res 184:29-37. CrossRef Medline

Upadhyay J, Maleki N, Potter J, Elman I, Rudrauf D, Knudsen J, Wallin D, Pendse G, McDonald L, Griffin M, Anderson J, Nutile L, Renshaw P, Weiss R, Becerra L, Borsook D (2010) Alterations in brain structure and functional connectivity in prescription opioid-dependent patients. Brain 133:2098-2114. CrossRef Medline

Vassoler FM, White SL, Hopkins TJ, Guercio LA, Espallergues J, Berton O, Schmidt HD, Pierce RC (2013) Deep brain stimulation of the nucleus accumbens shell attenuates cocaine reinstatement through local and antidromic activation. J Neurosci 33:14446-14454. CrossRef Medline

Vogt BA, Paxinos G (2014) Cytoarchitecture of mouse and rat cingulate cortex with human homologies. Brain Struct Funct 219:185-192. CrossRef Medline

Volkow ND, Baler RD, Goldstein RZ (2011a) Addiction: pulling at the neural threads of social behaviors. Neuron 69:599-602. CrossRef Medline

Volkow ND, Wang GJ, Fowler JS, Tomasi D, Telang F (2011b) Addiction: beyond dopamine reward circuitry. Proc Natl Acad Sci U S A 108:1503715042. CrossRef Medline

Wise SP (2008) Forward frontal fields: phylogeny and fundamental function. Trends Neurosci 31:599-608. CrossRef Medline

Wobrock T, Kamer T, Roy A, Vogeley K, Schneider-Axmann T, Wagner M, Maier W, Rietschel M, Schulze TG, Scherk H, Schild HH, Block W, Träber F, Tepest R, Honer WG, Falkai P (2008) Reduction of the internal capsule in families affected with schizophrenia. Biol Psychiatry 63:65-71. CrossRef Medline

Zhu X, Wang X, Xiao J, Zhong M, Liao J, Yao S (2011) Altered white matter integrity in first-episode, treatment-naive young adults with major depressive disorder: a tract-based spatial statistics study. Brain Res 1369: 223-229. CrossRef Medline

Zou LQ, Xie JX, Yuan HS, Pei XL, Dong WT, Liu PC (2008) Diffusion tensor imaging study of the anterior limb of internal capsules in neurolepticnaive schizophrenia. Acad Radiol 15:285-289. CrossRef Medline 